\title{
增密减氮对棉花干物质和氮素积累分配及产量的影响
}

\author{
王士红 ${ }^{1,2}$ 杨中㝵 ${ }^{2}$ 史加亮 ${ }^{3}$ 李海涛 $^{2}$ 宋宪亮 ${ }^{1, *}$ 孙学振 ${ }^{1, *}$
}

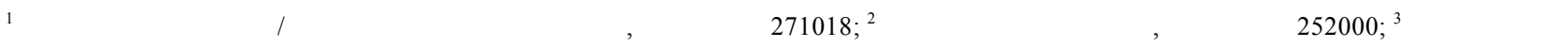
学研究院, 山东德州 253000

摘 要: 为了探讨种植密度和施氮量对棉花干物质与氮素积累分配及产量的影响。本研究以聊棉 6 号为试验材料, 设 置 5.25、6.75 和 8.25 万株 $\mathrm{hm}^{-2}\left(\mathrm{D}_{5.25} 、 \mathrm{D}_{6.75} 、 \mathrm{D}_{8.25}\right) 3$ 个种植密度, $0 、 105 、 210 、 315$ 和 $420 \mathrm{~kg} \mathrm{hm}{ }^{-2}\left(\mathrm{~N}_{0} 、 \mathrm{~N}_{105} 、 \mathrm{~N}_{210} 、\right.$ $\left.\mathrm{N}_{315} 、 \mathrm{~N}_{420}\right) 5$ 个施氮量，研究增密减氮对棉花干物质积累与分配、氮素积累与分配、产量及其构成因素的影响。结果 表明，与 $\mathrm{D}_{5.25}$ 相比， $\mathrm{D}_{6.75} 、 \mathrm{D}_{8.25}$ 条件下棉花干物质积累量显著升高, 2016 年提高了 $17.6 \% 、 28.7 \%, 2017$ 年提高了 $12.6 \%$ 、 $20.9 \%$ 。与 $\mathrm{N}_{0}$ 相比, 施氮肥后干物质积累量随施氮量的增加显著升高, 2016 年各施氮处理分别提高了 $4.5 \%$ 、 $11.1 \%$ 、 $13.7 \% 、 16.3 \%, 2017$ 年提高了 $3.6 \% 、 13.5 \% 、 15.3 \% 、 19.8 \%$ 。棉花氮素吸收与干物质积累动态曲线均符合 Logistic 模 型, 2 年间棉株氮素最大累积量 $\left(Y_{\mathrm{m}}\right)$ 均在 $\mathrm{D}_{8.25} \mathrm{~N}_{420}$ 处理下获得, 与平均值相比, 棉株氮素最大累积量分别提高了 $17.3 \%$ 和 $23.8 \%$ 、快速累积持续时间( $T$ )延长了 $5.2 \%$ 和 $9.9 \%$ 、最大累积速率 $\left(V_{\mathrm{m}}\right)$ 提升 $11.5 \%$ 和 $13.8 \%$, 氮素快速积累期起始 时期 $\left(t_{1}\right)$ 比干物质积累分别提早了 $4.1 \mathrm{~d}$ 和 $6.4 \mathrm{~d} 。 2016$ 年 $\mathrm{D}_{5.25} \mathrm{~N}_{315} 、 \mathrm{D}_{6.75} \mathrm{~N}_{210} 、 \mathrm{D}_{6.75} \mathrm{~N}_{105}$ 和 2017 年 $\mathrm{D}_{5.25} \mathrm{~N}_{315} 、 \mathrm{D}_{6.75} \mathrm{~N}_{210}$ 处理的棉花产量显著高于其他处理。种植密度和施氮量的互作效应对棉花产量的影响显著, 增密减氮可以获得高产, 推荐本地区棉花种植密度从常规的 5.25 万株 $\mathrm{hm}^{-2}$ 增加到 6.75 万株 $\mathrm{hm}^{-2}$, 施氮量从常规的 $300 \mathrm{~kg} \mathrm{hm}$ 第一年减少 为 $105 \mathrm{~kg} \mathrm{hm}^{-2}$, 第二年减少为 $210 \mathrm{~kg} \mathrm{hm}^{-2}$ 。

关键词: 棉花; 种植密度; 施氮量; 干物质; 产量

\section{Effects of increasing planting density and decreasing nitrogen rate on dry mat- ter, nitrogen accumulation and distribution, and yield of cotton}

WANG Shi-Hong ${ }^{1,2}$, YANG Zhong-Xu ${ }^{2}$, SHI Jia-Liang ${ }^{3}$, LI Hai-Tao ${ }^{2}$, SONG Xian-Liang ${ }^{1, *}$, and SUN Xue-Zhen ${ }^{1, *}$

\footnotetext{
${ }^{1}$ Agronomy College, Shandong Agricultural University / State Key Laboratory of Crop Biology, Tai'an 271018, Shandong, China; ${ }^{2}$ Liaocheng Academy of Agricultural Science, Liaocheng 252000, Shandong, China; ${ }^{3}$ Dezhou Academy of Agricultural Science, Dezhou 253000, Shandong, China
}

\begin{abstract}
A field experiment was conducted using Liaomian 6 with the treatments of three plant densities $\left(5.25 \times 10^{4}, 6.75 \times 10^{4}\right.$, and $8.25 \times 10^{4}$ plants $\mathrm{hm}^{-2}$ ), and five nitrogen rates $\left(0,105,210,315\right.$, and $\left.420 \mathrm{~kg} \mathrm{hm}^{-2}\right)$ in 2016 and 2017. Compared with $\mathrm{D}_{5.25}$, $\mathrm{D}_{6.75}$, and $\mathrm{D}_{8.25}$ dry matter accumulation of cotton significantly increased by $17.6 \%$ and $28.7 \%$ in $2016,12.6 \%$ and $20.9 \%$ in 2017 , respectively. Compared with $\mathrm{N}_{0}, \mathrm{~N}_{105}, \mathrm{~N}_{210}, \mathrm{~N}_{315}$, and $\mathrm{N}_{420}$ increased dry matter accumulation by $4.5 \%, 11.1 \%, 13.7 \%, 16.3 \%$ in 2016 and $3.6 \%, 13.5 \%, 15.3 \%, 19.8 \%$ in 2017 , respectively. The dynamic curve of cotton dry matter and nitrogen absorption accumulation conformed to the Logistic model, and the maximal nitrogen accumulation $\left(Y_{\mathrm{m}}\right)$ was obtained under $\mathrm{D}_{8.25} \mathrm{~N}_{420}$ treatment in 2016 and 2017. Compared to the average, the maximal biomass, duration of rapid accumulation $(T)$, the maximal speed of accumulation $\left(V_{\mathrm{m}}\right)$ increased by $17.3 \%$ and $23.8 \%, 5.20 \%$ and $9.9 \%, 11.45 \%$ and $13.8 \%$, respectively in two years. The starting date
\end{abstract}

本研究由国家自然科学基金项目(31601253), 国家现代农业产业技术体系(棉花)建设专项(CARS-18-37), 山东省现代农业产业技术体 系(棉花)建设专项(SDAIT-03)和山东省自然科学基金项目(ZR2016CQ20)资助。

This study was supported by the National Natural Science Foundation of China (31601253), the China Agriculture Research System (Cotton) (CARS-18-37), the Modern Agricultural Industry Technology System of Cotton Construction in Shandong Province (SDAIT-03), and the Natural Science Foundation of Shandong Province (ZR2016CQ20).

*通信作者(Corresponding authors): 孙学振, E-mail: sunxz@sdau.edu.cn; 宋宪亮, E-mail: xlsong@sdau.edu.cn

第一作者联系方式: E-mail: wshguyu@126.com

Received (收稿日期): 2019-05-15; Accepted (接受日期): 2019-09-26; Published online (网络出版日期): 2019-10-09.

URL: http://kns.cnki.net/kcms/detail/11.1809.S.20191008.1708.002.html 
of rapid accumulation period $\left(t_{1}\right)$ was $4.1 \mathrm{~d}$ and $6.4 \mathrm{~d}$ earlier for nitrogen than for dry matter, indicating that the nutrient absorption of cotton was the premise of dry matter accumulation. The lint yield of $\mathrm{D}_{5.25} \mathrm{~N}_{315}, \mathrm{D}_{6.75} \mathrm{~N}_{210}$ and $\mathrm{D}_{6.75} \mathrm{~N}_{105}$ in 2016 as well as $\mathrm{D}_{5.25} \mathrm{~N}_{315}$ and $\mathrm{D}_{6.75} \mathrm{~N}_{210}$ in 2017 was significantly higher than that of other treatments. The interaction effect of planting density and nitrogen application amount significantly affected cotton yield. Increasing planting density and reducing nitrogen application amount can obtain high yield. It is recommended for this region that the cotton planting density should be increased from $5.25 \times 10^{4}$ to $6.75 \times 10^{4}$ plants $\mathrm{hm}^{-2}$, and the amount of nitrogen application decreased from $300 \mathrm{~kg} \mathrm{hm}^{-2}$ to $105 \mathrm{~kg} \mathrm{hm}^{-2}$ in the first year, and then to $210 \mathrm{~kg} \mathrm{hm}^{-2}$ in the next year.

Keywords: cotton; plant density; nitrogen rate; dry matter; yield

棉花是我国重要的经济作物, 种植面积约占世 界的 $15 \%$ ，产量占世界的 $25 \%{ }^{[1]}$ 。国家统计局统计 2018 年全国棉花种植面积为 335.2 万公顷, 其中山 东省种植面积 18.3 万公顷, 位于全国 31 个省(区、 市)第三位。山东省是我国棉花重要产区, 同时又是 氮肥投入较多的省份, 高产棉田普遍存在投入氮肥 过量的问题, 由此造成肥料利用率低、生产成本高, 并对环境造成威胁, 降低氮肥用量势在必行。棉花 高产是以较高的生物量为前提, 而生物量累积是以 养分吸收为基础 ${ }^{[2]}$ 。种植密度和施氮量是棉花生产 中的重要调控因子, 合理种植密度能为棉花群体提 供适宜生物量, 调节群体与个体之间的矛盾, 使个 体发育壮而不衰, 单位面积株数、单株结铃数、单 铃质量得到协同发展, 从而实现棉花高产, 合理施 氮量为群体与个体的生长发育提供充足的养分, 有 利于平衡营养生长和生殖生长的关系, 达到棉花高 产优质的目标。有关种植密度和施氮量对作物产量 的影响研究报道较多, 研究者普遍认为在一定范围 内单位面积群体产量随密度的增加而增加, 当密度 达到一定程度时, 产量可达最高值, 如再继续增加 密度, 产量反而会下降 ${ }^{[3-8]}$, 施氮量过多会引起棉花 群体与个体、营养生长和生殖生长矛盾加剧, 造成 棉株干物质积累量增加, 出现蕾铃大量脱落, 经济 产量显著降低, 同时造成巨大的能源浪费和环境污 染 ${ }^{[9-10]}$ 。由此看来, 种植密度和施氮量在棉花生长中 只有维持平衡、协调的关系, 才能发挥对棉花生长 最佳的互作效应, 保证棉花正常生长。在降低氮肥 用量, 保护生态环境的同时, 如何稳定棉花产量、改 善棉花品质, 实现可持续性生产还少有报道。本试 验选择 3 个种植密度、5 个施氮量, 连续 2 年研究其 对棉花干物质和氮素积累分配的影响, 旨在探讨二 者对棉花产量构成的影响, 为棉花生产合理密植及 优化施氮提供理论依据。

\section{1 材料与方法}

\section{1 试验基本情况}

供试品种聊棉 6 号由聊城市农业科学院选育。
试验于 2016 年、2017 年在山东农业大学棉花科研 基地聊城市茌平县振兴办事处 $\left(36^{\circ} 31^{\prime} \mathrm{N}, 116^{\circ} 16^{\prime} \mathrm{E}\right)$ 进 行。试验地为连作 7 年以上的棉田, 一年一熟, 每年进 行秸秆还田。土壤质地为黏土, $0 \sim 20 \mathrm{~cm}$ 土壤含有机质 $13.7 \mathrm{~g} \mathrm{~kg}^{-1}$ 、全氮 $0.91 \mathrm{~g} \mathrm{~kg}^{-1}$ 、碱解氮 $63.8 \mathrm{mg} \mathrm{kg}^{-1}$ 、 速效磷 $26.5 \mathrm{mg} \mathrm{kg}^{-1}$ 、速效钾 $189.2 \mathrm{mg} \mathrm{kg}^{-1}, \mathrm{pH}$ 为 7.7 。2 年试验各处理为定位试验。

\section{2 试验设计}

设 $5.25\left(\mathrm{D}_{5.25}\right) 、 6.75\left(\mathrm{D}_{6.75}\right) 、 8.25\left(\mathrm{D}_{8.25}\right)$ 万株 $\mathrm{hm}^{-2}$ 3 个密度处理, $0\left(\mathrm{~N}_{0}\right) 、 105\left(\mathrm{~N}_{105}\right) 、 210\left(\mathrm{~N}_{210}\right) 、 315\left(\mathrm{~N}_{315}\right)$ 和 $420\left(\mathrm{~N}_{420}\right) \mathrm{kg} \mathrm{hm}^{-2} 5$ 个施氮量处理, 尿素为肥源, 按照当地施肥习惯将尿素分 2 次施入, 基追比 $1: 1$ 。 采用裂区设计, 主区为密度, 副区为施氮量, 3 次重 复, 小区行长 $10 \mathrm{~m}, 10$ 行区, 行距 $76 \mathrm{~cm}$, 小区面积 $76 \mathrm{~m}^{2}$ 。2 年均于 4 月 25 日机械播种, 地膜覆盖, $\mathrm{P}_{2} \mathrm{O}_{5}$ (过磷酸钙) 和 $\mathrm{K}_{2} \mathrm{O}$ (硫酸钾) 施用量分别为 90 、 $105 \mathrm{~kg} \mathrm{hm}^{-2}$, 基施氮肥和全部磷钾肥播种时集中开 沟条施, 距播种行 $10 \mathrm{~cm}$ 深 $10 \mathrm{~cm}$ 土壤中, 于 7 月 上旬开沟追施氮肥, 2 年缩节胺使用量相同, 分别 为现蕾期 $22.5 \mathrm{~g} \mathrm{hm}^{-2}$ 、初花期 $45 \mathrm{~g} \mathrm{hm}^{-2}$ 、盛花期 $67.5 \mathrm{~g} \mathrm{hm}^{-2}$ 、花铃期 $90 \mathrm{~g} \mathrm{hm}^{-2}$, 其他栽培管理措施 同一般大田。

\section{3 棉花生长季气象条件}

2016-2017 年棉花生长季气象条件如图 1 所示, 播种后 $0 \sim 150 \mathrm{~d}$ 降雨量分别为 $515.50 \mathrm{~mm}$ 、 $432.30 \mathrm{~mm}$, 平均气温为 $23.49^{\circ} \mathrm{C} 、 24.16^{\circ} \mathrm{C}$, 平均日 照时数为 $6.55 \mathrm{~h} 、 7.27 \mathrm{~h}$ 。

\section{4 测定项目与方法}

1.4.1 产量及构成因素测定分别于7月 15 日、 8 月 15 日、9 月 15 日选择每小区中间 4 行, 每行 两头分别去除 3 株后调查株数及总成铃数, 计算 单株成铃数。吐絮后分 3 期收获, 收获时间分别为 9 月 15 日、10月 30 日、11月 10 日，籽棉晒干后 称重计产, 计算单铃重, 轧花后称其皮棉重, 计算 衣分。 


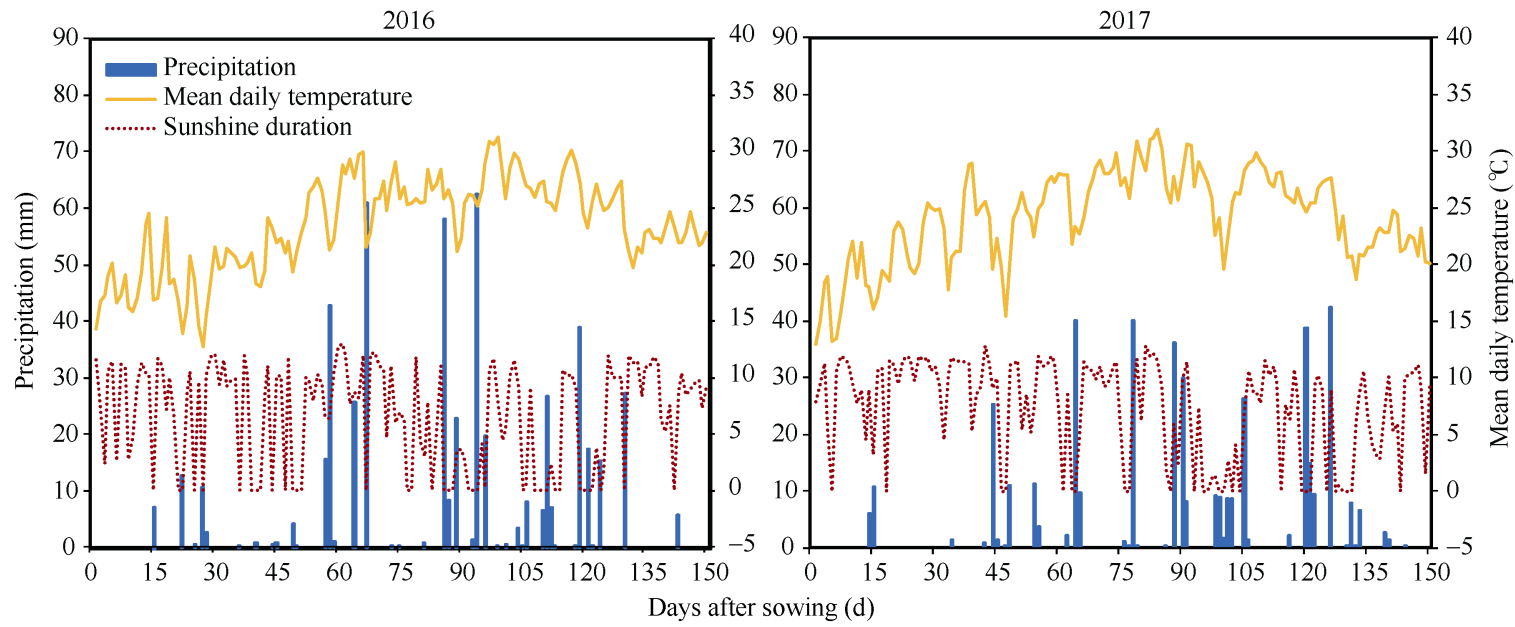

图 12016 年和 2017 年棉花生长季降雨量、平均气温和日照时数

Fig. 1 Mean daily temperature, precipitation, and sunshine duration of cotton growing season in 2016 and 2017

\subsection{2 干物质和氮素测定 分别于播种后 30 、} $60 、 90 、 120 、 150 \mathrm{~d}$ 按小区连续选取棉株 5 株，将 每株分为营养器官和生殖器官两部分, $105^{\circ} \mathrm{C}$ 杀青 30 $\min , 80^{\circ} \mathrm{C}$ 烘干至恒重, 测定干物质重。将烘干的棉 株样品粉碎, 过 $0.5 \mathrm{~mm}$ 篮, 用 $\mathrm{H}_{2} \mathrm{SO}_{4}-\mathrm{H}_{2} \mathrm{O}_{2}$ 消煮、蒸 馏定氮法测定各器官氮含量。

单位面积干物质积累量 $\left(\mathrm{kg} \mathrm{hm}^{-2}\right)=$ 不同时期单 株干物重 $(\mathrm{g}) \times$ 种植密度 $\left(\right.$ plant $\left.\mathrm{hm}^{-2}\right) / 1000$

单位面积氮素积累量 $\left(\mathrm{kg} \mathrm{hm}^{-2}\right)=$ 不同时期单株 干物重 $(\mathrm{g}) \times$ 单株含氮量 $(\%) \times$ 种植密度 $\left(\right.$ plant $\left.\mathrm{hm}^{-2}\right) /$ 1000

利用 logistic 曲线拟合棉花干物质和氮素积累量。

$$
Y=\frac{K}{1+a \mathrm{e}^{b t}}
$$

式中, $Y$ 为积累量 $\left(\mathrm{kg} \mathrm{hm}^{-2}\right), K$ 为理论最大积累量 $(\mathrm{kg}$ $\left.\mathrm{hm}^{-2}\right), t$ 为生长天数(d)。分别对公式(1)求一阶、二阶、 三阶导数, 得到相应生长曲线的快速积累期起始时 期 $\left(t_{1}\right)$ 、快速积累期终止时期 $\left(t_{2}\right)$ 、最大积累速率 $\left(V_{\mathrm{m}}\right)$ 、 最大积累速率出现时间 $\left(t_{\mathrm{m}}\right)$ 。

$$
\begin{aligned}
& t_{1}=\frac{1}{b} \ln \frac{2+\sqrt{3}}{a} \\
& t_{2}=\frac{1}{b} \ln \frac{2-\sqrt{3}}{a} \\
& t_{m}=-\frac{\ln a}{b} \\
& V_{m}=\frac{b K}{4}
\end{aligned}
$$

\section{5 数据处理}

采用 SPSS19.0 分析数据 Microsoft Excel 2007
绘制图表。

\section{2 结果与分析}

\section{1 干物质积累动态特征}

由表 1 可知, 随着种植密度增加, 棉花干物质 最大累积量 $\left(Y_{\mathrm{m}}\right)$ 升高, 而随着施氮量增加, 2 年的变 化不同。2016 年, 随着种植密度增加, 棉株干物质 和最大积累速率 $\left(V_{\mathrm{m}}\right)$ 升高, 快速积累期终止时期 $\left(t_{2}\right)$ 和最大积累速率出现时间 $\left(t_{\mathrm{m}}\right)$ 推后, 快速积累持续 期 $(T)$ 延长; 随着施氮量增加, 棉株干物质最大累积 量呈先升高后降低趋势, 最大积累速率升高, 快速 积累期起始时期 $\left(t_{1}\right)$ 、快速积累期终止时期和最大积 累速率出现时间提前, 快速积累持续期缩短; 种植 密度和施氮量互作下, 棉株干物质最大累积量在 $\mathrm{D}_{8.25} \mathrm{~N}_{210}$ 获得最大值, 其快速累积持续时间为 $47.3 \mathrm{~d}$, 最大累积速率为 $235.4 \mathrm{~kg} \mathrm{hm}^{-2} \mathrm{~d}^{-1}$, 与各处理平均值 相比，棉株干物质最大累积量提高了 $21.5 \%$, 快速 累积持续时间延长了 $11.2 \%$, 最大累积速率提升了 $9.6 \%$ 。2017 年, 随着种植密度增加, 棉株干物质最 大累积量升高, 快速积累期起始时期提前, 快速积 累期终止时期、最大积累速率出现时间、快速积累 持续期先缩短后延长，最大积累速率先升高后降低; 随着施氮量增加，棉株干物质最大累积量和最大积 累速率升高, 快速积累期起始时期延长; 两者互作 条件下, 棉株干物质最大累积量在 $\mathrm{D}_{8.25} \mathrm{~N}_{420}$ 取得最 大值, 其快速累积持续时间为 $45.5 \mathrm{~d}$, 最大累积速率 为 $223.6 \mathrm{~kg} \mathrm{hm}^{-2} \mathrm{~d}^{-1}$, 与平均值相比, 棉株干物质最 大累积量提高了 $22.1 \%$, 快速累积持续时间延长了 $7.5 \%$ ，最大累积速率提升了 $14.0 \%$ 。 
表 1 不同种植密度和施氮量棉花干物质累积动态特征值

Table 1 Eigen values of cotton dry matter accumulation dynamics under different nitrogen fertilizer rate and planting density treatments

\begin{tabular}{|c|c|c|c|c|c|c|c|c|c|c|c|c|}
\hline \multirow{2}{*}{$\begin{array}{c}\text { 处理 } \\
\text { Treatment }\end{array}$} & \multicolumn{6}{|c|}{2016} & \multicolumn{6}{|c|}{2017} \\
\hline & $\begin{array}{c}Y_{\mathrm{m}} \\
\left(\mathrm{kg} \mathrm{hm}^{-2}\right)\end{array}$ & $\begin{array}{c}t_{1} \\
\text { (d) }\end{array}$ & $\begin{array}{c}t_{2} \\
\text { (d) }\end{array}$ & $\begin{array}{l}t_{\mathrm{m}} \\
\text { (d) }\end{array}$ & $\begin{array}{c}V_{\mathrm{m}} \\
\left(\mathrm{kg} \mathrm{hm}^{-2} \mathrm{~d}^{-1}\right)\end{array}$ & $\begin{array}{c}T \\
\text { (d) }\end{array}$ & $\begin{array}{c}Y_{\mathrm{m}} \\
\left(\mathrm{kg} \mathrm{hm}^{-2}\right)\end{array}$ & $\begin{array}{c}t_{1} \\
\text { (d) }\end{array}$ & $\begin{array}{c}t_{2} \\
\text { (d) }\end{array}$ & $\begin{array}{l}t_{\mathrm{m}} \\
(\mathrm{d})\end{array}$ & $\begin{array}{c}V_{\mathrm{m}} \\
\left(\mathrm{kg} \mathrm{hm}^{-2} \mathrm{~d}^{-1}\right)\end{array}$ & $\begin{array}{l}T \\
\text { (d) }\end{array}$ \\
\hline
\end{tabular}

种植密度 Plant density $\left(\times 10^{4}\right.$ plants $\left.\mathrm{hm}^{-2}\right)$

$\begin{array}{lllllllllllll}\mathrm{D}_{5.25} & 11363.4 & 72.1 & 110.1 & 91.1 & 197.3 & 38.0 & 11390.2 & 67.5 & 108.1 & 87.8 & 184.3 & 40.6 \\ \mathrm{D}_{6.75} & 14377.1 & 73.8 & 116.7 & 95.3 & 221.5 & 42.8 & 12545.3 & 66.2 & 106.7 & 86.5 & 203.7 & 40.6 \\ \mathrm{D}_{8.25} & 15902.2 & 72.0 & 118.7 & 95.4 & 225.6 & 46.7 & 13935.1 & 66.1 & 111.9 & 89.0 & 200.5 & 45.8\end{array}$

施氮量 $\mathrm{N}$ rate $\left(\mathrm{kg} \mathrm{hm}^{-2}\right)$

$\begin{array}{lllllllllllll}\mathrm{N}_{0} & 12925.3 & 73.7 & 117.0 & 95.4 & 195.1 & 43.3 & 10891.9 & 64.6 & 106.3 & 85.5 & 172.0 & 41.7 \\ \mathrm{~N}_{105} & 13469.8 & 72.8 & 116.2 & 94.5 & 205.7 & 43.3 & 11955.7 & 65.9 & 108.2 & 87.1 & 186.0 & 42.3 \\ \mathrm{~N}_{210} & 14235.7 & 72.8 & 115.0 & 94.0 & 221.2 & 42.2 & 12996.6 & 66.8 & 109.3 & 88.0 & 201.2 & 42.5 \\ \mathrm{~N}_{315} & 14595.4 & 72.2 & 114.7 & 93.4 & 225.2 & 42.5 & 13117.0 & 66.9 & 108.4 & 87.7 & 207.9 & 41.5 \\ \mathrm{~N}_{420} & 14178.2 & 71.6 & 112.7 & 92.2 & 226.7 & 41.1 & 14156.4 & 68.7 & 112.2 & 90.4 & 213.7 & 43.6\end{array}$

种植密度 $\times$ 施氮量 Plant density $\times \mathrm{N}$ rate

\begin{tabular}{|c|c|c|c|c|c|c|c|c|c|c|c|c|}
\hline $\mathrm{D}_{5.25} \times \mathrm{N}_{0}$ & 10330.1 & 72.5 & 110.7 & 91.6 & 178.5 & 38.1 & 10044.1 & 66.2 & 104.7 & 85.5 & 171.8 & 38.5 \\
\hline $\mathrm{D}_{5.25} \times \mathrm{N}_{105}$ & 10976.7 & 72.2 & 110.5 & 91.4 & 189.5 & 38.2 & 10370.4 & 66.0 & 105.5 & 85.7 & 172.6 & 39.5 \\
\hline $\mathrm{D}_{5.25} \times \mathrm{N}_{210}$ & 11632.4 & 72.4 & 109.7 & 91.0 & 205.5 & 37.3 & 11781.5 & 67.7 & 109.0 & 88.3 & 187.5 & 41.3 \\
\hline $\mathrm{D}_{5.25} \times \mathrm{N}_{315}$ & 12084.2 & 71.5 & 110.2 & 90.8 & 206.3 & 38.6 & 11908.0 & 67.9 & 108.8 & 88.4 & 191.4 & 40.9 \\
\hline $\mathrm{D}_{5.25} \times \mathrm{N}_{420}$ & 11793.4 & 71.7 & 109.4 & 90.5 & 206.7 & 37.7 & 12847.2 & 69.7 & 112.3 & 91.0 & 198.1 & 42.6 \\
\hline $\mathrm{D}_{6.75} \times \mathrm{N}_{0}$ & 13856.2 & 75.3 & 120.2 & 97.8 & 202.5 & 44.9 & 10773.0 & 64.0 & 104.7 & 84.4 & 174.7 & 40.7 \\
\hline $\mathrm{D}_{6.75} \times \mathrm{N}_{105}$ & 14109.2 & 74.3 & 119.1 & 96.7 & 207.4 & 44.8 & 11976.6 & 66.2 & 106.1 & 86.2 & 197.7 & 39.9 \\
\hline $\mathrm{D}_{6.75} \times \mathrm{N}_{210}$ & 14215.0 & 73.1 & 115.2 & 94.2 & 222.7 & 42.1 & 12568.9 & 65.6 & 105.1 & 85.4 & 209.5 & 39.5 \\
\hline $\mathrm{D}_{6.75} \times \mathrm{N}_{315}$ & 15082.1 & 73.3 & 115.3 & 94.3 & 236.4 & 42.0 & 13201.8 & 66.8 & 106.9 & 86.9 & 217.0 & 40.1 \\
\hline $\mathrm{D}_{6.75} \times \mathrm{N}_{420}$ & 14623.0 & 73.0 & 113.5 & 93.3 & 238.4 & 40.4 & 14206.0 & 68.1 & 110.7 & 89.4 & 219.4 & 42.6 \\
\hline $\mathrm{D}_{8.25} \times \mathrm{N}_{0}$ & 14589.7 & 73.3 & 120.2 & 96.8 & 204.4 & 47.0 & 11858.7 & 63.7 & 109.6 & 86.7 & 169.6 & 46.0 \\
\hline $\mathrm{D}_{8.25} \times \mathrm{N}_{105}$ & 15323.4 & 72.0 & 118.9 & 95.4 & 220.2 & 46.9 & 13520.2 & 65.6 & 112.9 & 89.3 & 187.7 & 47.4 \\
\hline $\mathrm{D}_{8.25} \times \mathrm{N}_{210}$ & 16859.7 & 73.0 & 120.3 & 96.7 & 235.4 & 47.3 & 14639.3 & 67.1 & 113.7 & 90.4 & 206.5 & 46.7 \\
\hline $\mathrm{D}_{8.25} \times \mathrm{N}_{315}$ & 16619.8 & 71.7 & 118.6 & 95.2 & 233.0 & 47.0 & 14241.1 & 66.0 & 109.6 & 87.8 & 215.3 & 43.6 \\
\hline $\mathrm{D}_{8.25} \times \mathrm{N}_{420}$ & 16118.3 & 70.1 & 115.2 & 92.7 & 235.1 & 45.1 & 15416.1 & 68.2 & 113.7 & 90.9 & 223.6 & 45.5 \\
\hline 平均 Average & 13880.9 & 72.6 & 115.1 & 93.9 & 214.8 & 42.5 & 12623.5 & 66.6 & 108.9 & 87.8 & 196.2 & 42.3 \\
\hline
\end{tabular}

$\mathrm{D}_{5.25}$ ：种植密度 5.25 万株 $\mathrm{hm}^{-2} ; \mathrm{D}_{6.75}$ ：种植密度 6.75 万株 $\mathrm{hm}^{-2} ; \mathrm{D}_{8.25}$ ：种植密度 8.25 万株 $\mathrm{hm}^{-2} ; \mathrm{N}_{0}$ ：施氮量 $0 \mathrm{~kg} \mathrm{hm}$ 年; $\mathrm{N}_{105}$ ：施氮量 $105 \mathrm{~kg} \mathrm{hm}^{-2} ; \mathrm{N}_{210}$ : 施氮量 $210 \mathrm{~kg} \mathrm{hm}^{-2} ; \mathrm{N}_{315}$ : 施氮量 $315 \mathrm{~kg} \mathrm{hm}^{-2} ; \mathrm{N}_{420}$ : 施氮量 $420 \mathrm{~kg} \mathrm{hm}^{-2}$ 。 $Y_{\mathrm{m}}$ : 最大积累量; $t_{1}$ : 快速积累期起始时期; $t_{2}$ : 快速积累期终止时期; $V_{\mathrm{m}}$ : 最大积累速率; $t_{\mathrm{m}}$ : 最大积累速率出现时间; $T$ : 快速积累持续期。

$\mathrm{D}_{5.25}$ : density $5.25 \times 10^{4}$ plants $\mathrm{hm}^{-2} ; \mathrm{D}_{6.75}$ : density $6.75 \times 10^{4}$ plants $\mathrm{hm}^{-2} ; \mathrm{D}_{8.25}$ : density $8.25 \times 10^{4}$ plants $\mathrm{hm}^{-2} ; \mathrm{N}_{0}:$ nitrogen rate $0 \mathrm{~kg} \mathrm{hm}^{-2} ; \mathrm{N}_{105}$ : nitrogen rate $105 \mathrm{~kg} \mathrm{hm}^{-2} ; \mathrm{N}_{210}$ : nitrogen rate $210 \mathrm{~kg} \mathrm{hm}^{-2} ; \mathrm{N}_{315}$ : nitrogen rate $315 \mathrm{~kg} \mathrm{hm}^{-2} ; \mathrm{N}_{420}$ : nitrogen rate $420 \mathrm{~kg} \mathrm{hm}{ }^{-2} . Y_{\mathrm{m}}:$ maximal accumulation; $t_{1}$ : starting date of rapid accumulation period; $t_{2}$ : terminating date of rapid accumulation period; $V_{\mathrm{m}}$ : maximal speed of accumulation; $t_{\mathrm{m}}$ : time reached maximal rate of accumulation; $T$ : duration of rapid accumulation.

由图 2 可知, 随着生育进程, 棉花干物质积累 量呈“慢一快-慢”的 $\mathrm{S}$ 型曲线变化, 随着种植密度和 施氮量增加，棉花生育中后期干物质积累量升高。 2016 年, 随着种植密度增加, 收获期干物质积累量 表现为 $\mathrm{D}_{8.25}>\mathrm{D}_{6.75}>\mathrm{D}_{5.25}$, 与 $\mathrm{D}_{5.25}$ 相比, $\mathrm{D}_{6.75} 、 \mathrm{D}_{8.25}$ 条件下干物质积累量提高了 $17.6 \%$ 、28.7\%, 随着施 氮量增加, 收获期各施氮处理干物质积累量分别比
$\mathrm{N}_{0}$ 提高了 $4.5 \% 、 11.01 \% 、 13.7 \% 、 16.23 \%$ 。2017 年 与 2016 年表现相同, 干物质积累量均在 $\mathrm{D}_{8.25}$ 条件下 $\mathrm{N}_{420}$ 时取得最大值, 表明生育后期棉花营养器官生 长速度重新加快, 尤其是 $\mathrm{N}_{315} 、 \mathrm{~N}_{420}$ 表现更为明显, 施氮量过大会导致后期营养生长过旺，干物质积累 量大, 增加种植密度和施氮量可以显著提高棉花成 熟期干物质积累量。与 2016 年相比, 2017 年生育后 


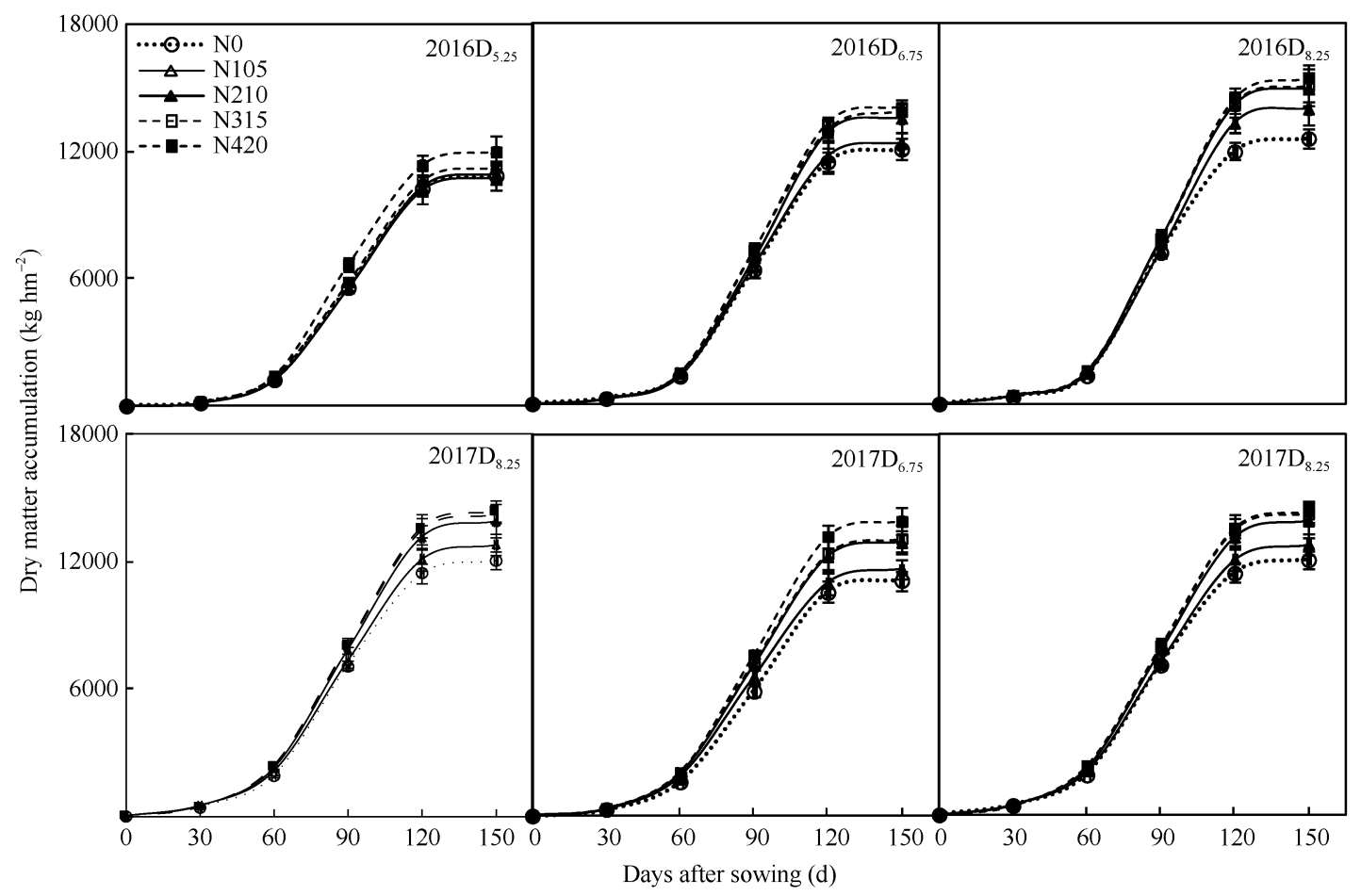

图 2 不同种植密度和施氮量处理下棉花干物质积累动态

Fig. 2 Dynamics of cotton biomass under different nitrogen fertilizer rate and planting density treatments 处理同表 1 。Treatments are the same as those given in Table 1 .

期 $\mathrm{D}_{8.25}$ 条件下, $\mathrm{N}_{315 、} \mathrm{~N}_{420}$ 干物质积累量明显降低, 原因是 2016 年阴雨寡照天气较多, 高密高氮处理会 造成营养生长旺盛, 干物质积累速率高, 积累量大。

\section{2 氮素积累动态特征}

由表 2 可知, 2016 年, 随着种植密度增加, 棉株 氮素最大累积量 $\left(Y_{\mathrm{m}}\right)$ 升高, 快速积累期起始时期 $\left(t_{1}\right)$ 、快速积累期终止时期 $\left(t_{2}\right)$ 和最大积累速率出现时 间 $\left(t_{\mathrm{m}}\right)$ 提前, 最大积累速率 $\left(V_{\mathrm{m}}\right)$ 先升高后降低, 快速 积累持续期 $(T)$ 先缩短后延长; 不同施氮量处理间, 棉株干物质最大累积量和最大积累速率在 $\mathrm{N}_{315}$ 时获 得最大值, 其他各特征值则在 $\mathrm{N}_{210}$ 时获得最大值; 两者互作条件下，棉株氮素最大累积量在 $\mathrm{D}_{8.25} \mathrm{~N}_{420}$ 达到最大值, 其快速累积持续时间为 $50.6 \mathrm{~d}$, 最大累 积速率为 $3.9 \mathrm{~kg} \mathrm{hm}^{-2} \mathrm{~d}^{-1}$, 与各处理平均值相比, 棉 株氮素最大累积量提高了 $17.3 \%$, 快速累积持续时 间延长了 $5.2 \%$ ，最大累积速率提升了 $11.5 \%$ 。2017 年, 随着种植密度增加, 棉株氮素最大累积量先升 高后降低, 其他各特征值的变化趋势与 2016 年相同; 不同施氮量处理间，除最大积累速率外，其他各特 征值均在 $\mathrm{N}_{420}$ 时取得最大值; 两者互作条件下, 棉 株氮素最大累积量在 $\mathrm{D}_{8.25} \mathrm{~N}_{420}$ 取得最大值, 其快速
累积持续时间为 $46.4 \mathrm{~d}$, 最大累积速率为 $4.1 \mathrm{~kg} \mathrm{hm}^{-2}$ $\mathrm{d}^{-1}$, 与各处理平均值相比, 棉株氮素最大累积量提 高了 $23.8 \%$, 快速累积持续时间延长了 $9.9 \%$, 最大 累积速率提升了 $13.8 \%$, 与 2016 年相比, 2017 年最 快累积起始时间早, 结束时间早, 且氮素快速累积 时间短, 这也是氮素积累量低的主要原因。与干物 质相比, 氮素快速积累期起始时间早 4.1 6.4 d, 最 大积累速率出现时间早 1.4 6.6 d, 棉花养分吸收高 峰期的出现早于干物质积累, 说明氮素积累是干物 质积累的基础。

由图 3 可知, 各个时期棉花氮素积累量与干物 质积累量的变化相同, 随着生育进程, 氮素积累量 也呈“慢一快-慢”的 $\mathrm{S}$ 型曲线, 随着种植密度和施氮 量增加, 棉花生育中后期氮素积累量升高。2016 年, 不同密度处理间均表现为 $\mathrm{D}_{8.25}>\mathrm{D}_{6.75}>\mathrm{D}_{5.25}$, 与 $\mathrm{D}_{5.25}$ 相比, $\mathrm{D}_{6.75} 、 \mathrm{D}_{8.25}$ 条件下提高了 $6.3 \% 、 7.9 \%$; 不 同施氮量间随着施氮量增加而增加，与 $\mathrm{N}_{0}$ 相比，各 施氮处理间分别提高了 $19.5 \%$ 、30.0\%、38.2\%、 $38.3 \%$ 。2017 年与 2016 年表现相同，氮素积累量均 在高氮高密条件下取得高值, 高密度形成大群体, 大群体吸氮能力强, 高施氮量又为大群体提供充足 
表 2 不同种植密度和施氮量棉花氮素累积动态特征值

Table 2 Eigen values of cotton nitrogen accumulation dynamics under different nitrogen fertilizer rate and planting density treatments

\begin{tabular}{|c|c|c|c|c|c|c|c|c|c|c|c|c|}
\hline \multirow{2}{*}{$\begin{array}{c}\text { 处理 } \\
\text { Treatment }\end{array}$} & \multicolumn{6}{|c|}{2016} & \multicolumn{6}{|c|}{2017} \\
\hline & $\begin{array}{c}Y_{\mathrm{m}} \\
\left(\mathrm{kg} \mathrm{hm}^{-2}\right)\end{array}$ & $\begin{array}{l}t_{1} \\
\text { (d) }\end{array}$ & $\begin{array}{l}t_{2} \\
\text { (d) }\end{array}$ & $\begin{array}{l}t_{\mathrm{m}} \\
\text { (d) }\end{array}$ & $\begin{array}{c}V_{\mathrm{m}} \\
\left(\mathrm{kg} \mathrm{hm}^{-2} \mathrm{~d}^{-1}\right)\end{array}$ & $\begin{array}{c}T \\
\text { (d) }\end{array}$ & $\begin{array}{c}Y_{\mathrm{m}} \\
\left(\mathrm{kg} \mathrm{hm}^{-2}\right)\end{array}$ & $\begin{array}{l}t_{1} \\
\text { (d) }\end{array}$ & $\begin{array}{l}t_{2} \\
\text { (d) }\end{array}$ & $\begin{array}{l}t_{\mathrm{m}} \\
\text { (d) }\end{array}$ & $\begin{array}{c}V_{\mathrm{m}} \\
\left(\mathrm{kg} \mathrm{hm}^{-2} \mathrm{~d}^{-1}\right)\end{array}$ & $\begin{array}{c}T \\
\text { (d) }\end{array}$ \\
\hline
\end{tabular}

种植密度 Plant density $\left(\times 10^{4}\right.$ plants $\left.\cdot \mathrm{hm}^{-2}\right)$

\begin{tabular}{|c|c|c|c|c|c|c|c|c|c|c|c|c|}
\hline $\mathrm{D}_{5.25}$ & 245.7 & 71.7 & 119.5 & 95.6 & 3.4 & 47.8 & 223.4 & 62.3 & 105.5 & 83.9 & 3.4 & 43.2 \\
\hline $\mathrm{D}_{6.75}$ & 256.9 & 69.0 & 116.5 & 92.8 & 3.6 & 47.5 & 237.2 & 60.1 & 101.7 & 80.9 & 3.8 & 41.6 \\
\hline $\mathrm{D}_{8.25}$ & 260.0 & 64.7 & 113.7 & 89.2 & 3.5 & 49.0 & 235.7 & 58.1 & 99.8 & 79.0 & 3.7 & 41.7 \\
\hline
\end{tabular}

施氮量 $\mathrm{N}$ rate $\left(\mathrm{kg} \mathrm{hm}^{-2}\right)$

\begin{tabular}{|c|c|c|c|c|c|c|c|c|c|c|c|c|}
\hline $\mathrm{N}_{0}$ & 193.3 & 65.1 & 108.1 & 86.6 & 3.0 & 42.9 & 174.3 & 56.2 & 92.1 & 74.1 & 3.2 & 35.9 \\
\hline $\mathrm{N}_{105}$ & 245.6 & 69.2 & 118.9 & 94.1 & 3.3 & 49.7 & 218.5 & 59.2 & 102.5 & 80.9 & 3.3 & 43.2 \\
\hline $\mathrm{N}_{210}$ & 271.0 & 69.5 & 121.1 & 95.3 & 3.5 & 51.6 & 246.7 & 60.9 & 104.8 & 82.8 & 3.7 & 43.8 \\
\hline $\mathrm{N}_{315}$ & 281.1 & 69.4 & 117.6 & 93.5 & 3.9 & 48.2 & 255.1 & 61.7 & 104.2 & 82.9 & 4.0 & 42.5 \\
\hline $\mathrm{N}_{420}$ & 280.1 & 69.0 & 117.1 & 93.1 & 3.9 & 48.1 & 265.9 & 62.8 & 108.1 & 85.5 & 3.9 & 45.4 \\
\hline
\end{tabular}

种植密度 $\times$ 施氮量 Plant density $\times \mathrm{N}$ rate

\begin{tabular}{|c|c|c|c|c|c|c|c|c|c|c|c|c|}
\hline $\mathrm{D}_{5.25} \times \mathrm{N}_{0}$ & 192.2 & 69.4 & 112.4 & 90.9 & 3.0 & 43.0 & 171.7 & 58.8 & 95.2 & 77.0 & 3.1 & 36.4 \\
\hline $\mathrm{D}_{5.25} \times \mathrm{N}_{105}$ & 231.4 & 72.1 & 118.3 & 95.2 & 3.3 & 46.2 & 214.3 & 61.6 & 106.7 & 84.2 & 3.1 & 45.1 \\
\hline $\mathrm{D}_{5.25} \times \mathrm{N}_{210}$ & 258.0 & 72.0 & 122.3 & 97.2 & 3.4 & 50.3 & 239.8 & 63.0 & 107.2 & 85.1 & 3.6 & 44.2 \\
\hline $\mathrm{D}_{5.25} \times \mathrm{N}_{315}$ & 274.8 & 72.4 & 122.6 & 97.5 & 3.6 & 50.2 & 250.6 & 64.2 & 110.3 & 87.2 & 3.6 & 46.1 \\
\hline $\mathrm{D}_{5.25} \times \mathrm{N}_{420}$ & 271.9 & 72.4 & 121.8 & 97.1 & 3.6 & 49.4 & 240.6 & 63.9 & 108.1 & 86.0 & 3.6 & 44.2 \\
\hline $\mathrm{D}_{6.75} \times \mathrm{N}_{0}$ & 196.5 & 64.7 & 109.2 & 87.0 & 2.9 & 44.5 & 177.5 & 56.0 & 92.3 & 74.2 & 3.2 & 36.4 \\
\hline $\mathrm{D}_{6.75} \times \mathrm{N}_{105}$ & 254.7 & 70.3 & 121.5 & 95.9 & 3.3 & 51.2 & 223.0 & 59.5 & 101.6 & 80.6 & 3.5 & 42.0 \\
\hline $\mathrm{D}_{6.75} \times \mathrm{N}_{210}$ & 279.1 & 70.9 & 122.7 & 96.8 & 3.6 & 51.8 & 258.2 & 61.2 & 104.9 & 83.1 & 3.9 & 43.7 \\
\hline $\mathrm{D}_{6.75} \times \mathrm{N}_{315}$ & 284.0 & 70.1 & 115.8 & 92.9 & 4.1 & 45.7 & 257.5 & 61.6 & 101.9 & 81.7 & 4.2 & 40.3 \\
\hline $\mathrm{D}_{6.75} \times \mathrm{N}_{420}$ & 270.2 & 69.1 & 113.4 & 91.3 & 4.0 & 44.3 & 269.8 & 62.0 & 107.7 & 84.8 & 3.9 & 45.6 \\
\hline $\mathrm{D}_{8.25} \times \mathrm{N}_{0}$ & 191.1 & 61.3 & 102.6 & 81.9 & 3.1 & 41.3 & 173.6 & 53.7 & 88.8 & 71.3 & 3.3 & 35.1 \\
\hline $\mathrm{D}_{8.25} \times \mathrm{N}_{105}$ & 250.6 & 65.3 & 116.9 & 91.1 & 3.3 & 51.6 & 218.3 & 56.6 & 99.1 & 77.8 & 3.4 & 42.5 \\
\hline $\mathrm{D}_{8.25} \times \mathrm{N}_{210}$ & 275.9 & 65.5 & 118.2 & 91.9 & 3.5 & 52.7 & 242.2 & 58.5 & 102.1 & 80.3 & 3.7 & 43.6 \\
\hline $\mathrm{D}_{8.25} \times \mathrm{N}_{315}$ & 284.3 & 65.7 & 114.5 & 90.1 & 3.9 & 48.8 & 257.1 & 59.3 & 100.3 & 79.8 & 4.1 & 41.0 \\
\hline $\mathrm{D}_{8.25} \times \mathrm{N}_{420}$ & 298.1 & 65.6 & 116.2 & 90.9 & 3.9 & 50.6 & 287.4 & 62.4 & 108.7 & 85.6 & 4.1 & 46.4 \\
\hline 平均 Average & 254.2 & 68.5 & 116.6 & 92.5 & 3.5 & 48.1 & 232.1 & 60.2 & 102.3 & 81.2 & 3.6 & 42.2 \\
\hline
\end{tabular}

缩写同表 1。Abbreviations are the same as those given in Table 1.

的供氮能力, 有利于吸收更多的氮素, 为干物质积累奠 定基础。与 2016 年相比, 2017 年中高密度条件下氮素 积累量均显著降低, 决定了其干物质积累量也会降低。

\section{3 棉花干物质分配}

由表 3 可知, 不同种植密度和施氮量间干物质 分配到营养器官与生殖器官的量均差异极显著, 其 中 2016 年分配到生殖器官的量在两者互作条件下 差异极显著。2016 年, 随着种植密度增加, 干物质 分配到营养器官与生殖器官的量均显著提高, 随着 施氮量增加, 分配到营养器官的量呈升高趋势, $\mathrm{N}_{420}$ 显著高于其他处理, 且 $\mathrm{N}_{210}$ 与 $\mathrm{N}_{315}$ 差异不显著, 分
配到生殖器官的量呈先升高后降低趋势, $\mathrm{N}_{210}$ 、 $\mathrm{N}_{315} 、 \mathrm{~N}_{420}$ 间差异不显著，两者互作下，分配到营养 器官与生殖器官的量均在 $\mathrm{D}_{8.25} \mathrm{~N}_{420}$ 处理下取得最 大值，其分配比例分别为 $50.5 \%$ 、49.5\%。与 2016 年相比, 2017 年在不同种植密度和施氮量及其互作 条件下, 更多的干物质分配到生殖器官为获得高 产奠定基础。

\section{4 棉花氮素分配}

如表 4 所示, 2 年间氮素分配到营养器官与生殖 器官的量在不同种植密度和施氮量间差异显著或极 显著, 其中 2017 年营养器官与生殖器官的分配量在 


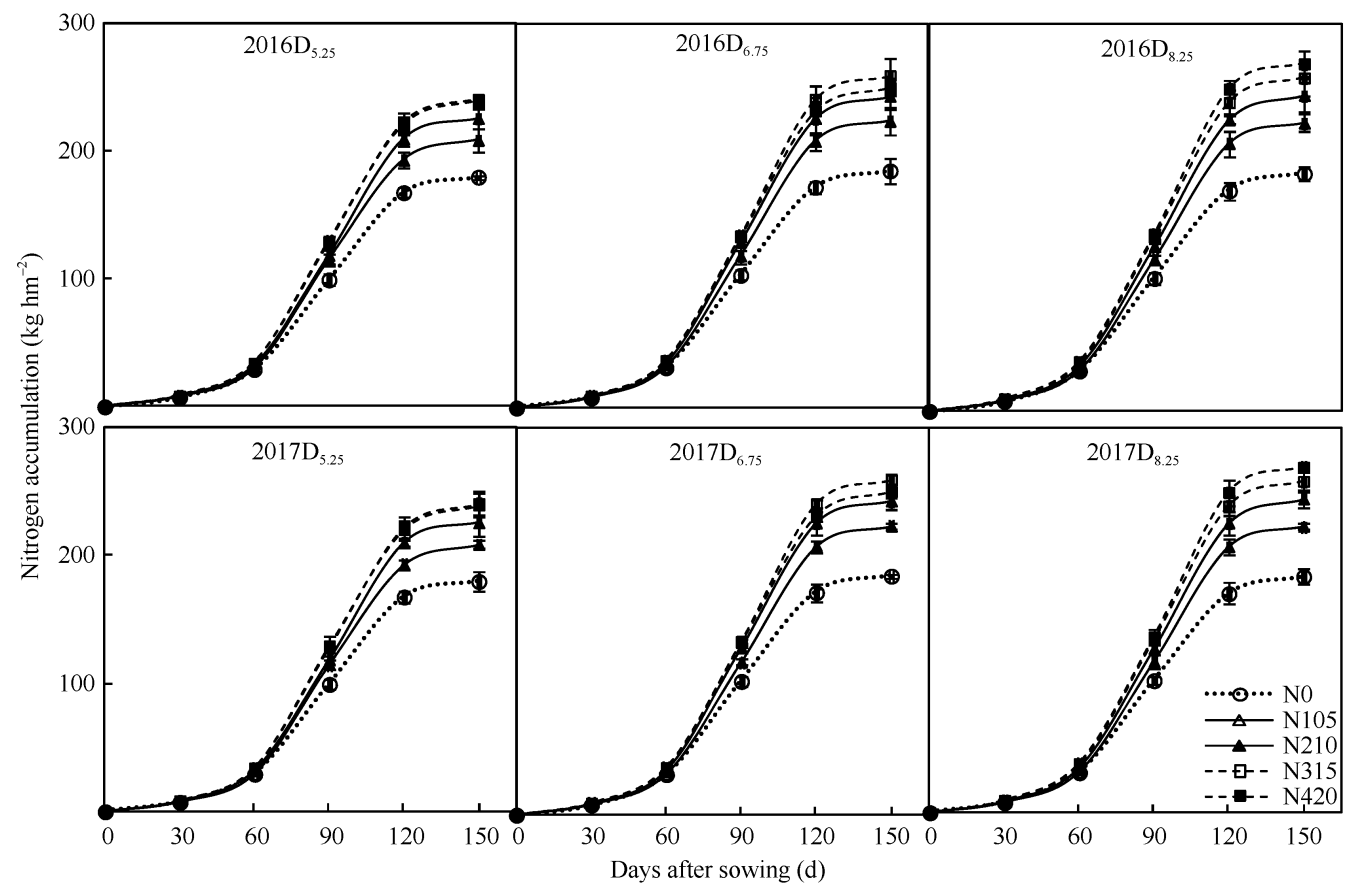

图 3 不同种植密度和施氮量处理下氮素积累动态

Fig. 3 Dynamics of nitrogen accumulation under different nitrogen fertilizer rate and planting density treatments 处理同表 1 。Treatments are the same as those given in Table 1.

表 3 种植密度和施氮量对棉花干物质分配的影响

Table 3 Effects of nitrogen application and planting density on dry matter distribution of cotton $\left(\mathrm{kg} \mathrm{hm}^{-2}\right)$

\begin{tabular}{|c|c|c|c|c|}
\hline \multirow{2}{*}{$\begin{array}{c}\text { 处理 } \\
\text { Treatment }\end{array}$} & \multicolumn{2}{|c|}{2016} & \multicolumn{2}{|c|}{2017} \\
\hline & $\begin{array}{c}\text { 营养器官分配量 } \\
\text { DVO }\end{array}$ & $\begin{array}{c}\text { 生殖器官分配量 } \\
\text { DRO }\end{array}$ & $\begin{array}{c}\text { 营养器官分配量 } \\
\text { DVO }\end{array}$ & $\begin{array}{c}\text { 生殖器官分配量 } \\
\text { DRO }\end{array}$ \\
\hline \multicolumn{5}{|c|}{ 种植密度 Plant density $\left(\times 10^{4}\right.$ plant $\left.\mathrm{hm}^{-2}\right)$} \\
\hline $\mathrm{D}_{5.25}$ & 5008.6 c (44.6) & 6184.5 c (55.4) & $4842.2 \mathrm{c}(43.3)$ & 6317.8 c (56.7) \\
\hline $\mathrm{D}_{6.75}$ & $6259.7 \mathrm{~b}(47.5)$ & $6902.1 \mathrm{~b}(52.5)$ & $5713.9 \mathrm{~b}(45.4)$ & $6847.5 \mathrm{~b}(54.6)$ \\
\hline $\mathrm{D}_{8.25}$ & 7114.0 a $(49.3)$ & 7286.1 a $(50.7)$ & $6406.1 \mathrm{a}(47.4)$ & 7082.7 a $(52.6)$ \\
\hline \multicolumn{5}{|l|}{ 施氮量 $\mathrm{N}$ rate $\left(\mathrm{kg} \mathrm{hm}^{-2}\right)$} \\
\hline $\mathrm{N}_{0}$ & $5365.9 \mathrm{~d}(45.2)$ & $6473.0 \mathrm{~b}(54.8)$ & $4910.9 \mathrm{~d}(43.6)$ & 6319.7 b (56.4) \\
\hline $\mathrm{N}_{105}$ & 5788.7 c $(46.5)$ & $6581.1 \mathrm{~b}(53.5)$ & 5155.9 c (44.1) & $6483.0 \mathrm{~b}(55.9)$ \\
\hline $\mathrm{N}_{210}$ & $6205.8 \mathrm{~b}(46.8)$ & 6944.8 a $(53.2)$ & $5855.4 \mathrm{~b}(45.8)$ & 6892.7 a $(54.2)$ \\
\hline $\mathrm{N}_{315}$ & $6462.8 \mathrm{~b}(47.7)$ & 7002.0 a $(52.3)$ & $5987.6 \mathrm{~b}(46.1)$ & 6956.9 a $(53.9)$ \\
\hline $\mathrm{N}_{420}$ & 6813.9 a (49.4) & 6953.6 a $(50.6)$ & 6360.7 a $(47.2)$ & 7094.4 a $(52.8)$ \\
\hline \multicolumn{5}{|c|}{ 种植密度 $\times$ 施氮量 Plant density $\times \mathrm{N}$ rate } \\
\hline $\mathrm{D}_{5.25} \times \mathrm{N}_{0}$ & $4725.7 \mathrm{~g}(43.4)$ & $6155.9 \mathrm{~d}(56.6)$ & $4326.7 \mathrm{f}(41.3)$ & $6142.7 \mathrm{~d}(58.7)$ \\
\hline $\mathrm{D}_{5.25} \times \mathrm{N}_{105}$ & $4633.6 \mathrm{~g}(42.8)$ & $6176.8 \mathrm{~d}(57.2)$ & $4297.0 \mathrm{f}(41.2)$ & 6139.7 d (58.8) \\
\hline $\mathrm{D}_{5.25} \times \mathrm{N}_{210}$ & $4742.6 \mathrm{~g} \mathrm{(43.2)}$ & $6234.7 \mathrm{~d}(56.8)$ & 5005.7 e $(44.0)$ & $6381.0 \mathrm{~d}(56.0)$ \\
\hline $\mathrm{D}_{5.25} \times \mathrm{N}_{315}$ & $5126.6 \mathrm{fg}(45.3)$ & $6160.1 \mathrm{~d}(54.7)$ & 5048.0 e $(44.1)$ & 6406.7 d (55.9) \\
\hline $\mathrm{D}_{5.25} \times \mathrm{N}_{420}$ & 5814.8 e (48.5) & $6195.2 \mathrm{~d}(51.5)$ & $5534.0 \mathrm{~cd}(45.9)$ & $6519.0 \mathrm{~cd}(54.1)$ \\
\hline $\mathrm{D}_{6.75} \times \mathrm{N}_{0}$ & 5455.1 ef (45.2) & 6606.5 c (54.8) & 4876.7 e $(43.8)$ & $6263.7 \mathrm{~d}(56.2)$ \\
\hline $\mathrm{D}_{6.75} \times \mathrm{N}_{105}$ & 5832.6 e (47.3) & $6497.9 \mathrm{~cd}(52.7)$ & 5202.0 de (44.6) & $6459.0 \mathrm{~cd}(55.4)$ \\
\hline $\mathrm{D}_{6.75} \times \mathrm{N}_{210}$ & $6432.6 \mathrm{~cd}(47.5)$ & $7091.3 \mathrm{~b}(52.5)$ & $5908.0 \mathrm{bc}(45.7)$ & $7032.7 \mathrm{ab}(54.3)$ \\
\hline $\mathrm{D}_{6.75} \times \mathrm{N}_{315}$ & $6753.8 \mathrm{c}(48.1)$ & $7289.7 \mathrm{ab}(51.9)$ & $5990.0 \mathrm{~b}(45.6)$ & $7133.0 \mathrm{ab}(54.4)$ \\
\hline $\mathrm{D}_{6.75} \times \mathrm{N}_{420}$ & 6824.5 c (49.3) & 7025.2 b (50.7) & 6593.0 a (47.3) & 7349.3 a (52.7) \\
\hline
\end{tabular}


(续表 3)

\begin{tabular}{|c|c|c|c|c|}
\hline \multirow{2}{*}{$\begin{array}{c}\text { 处理 } \\
\text { Treatment }\end{array}$} & \multicolumn{2}{|c|}{2016} & \multicolumn{2}{|c|}{2017} \\
\hline & $\begin{array}{c}\text { 营养器官分配量 } \\
\text { DVO }\end{array}$ & $\begin{array}{c}\text { 生殖器官分配量 } \\
\text { DRO }\end{array}$ & $\begin{array}{c}\text { 营养器官分配量 } \\
\text { DVO }\end{array}$ & $\begin{array}{c}\text { 生殖器官分配量 } \\
\text { DRO }\end{array}$ \\
\hline $\mathrm{D}_{8.25} \times \mathrm{N}_{0}$ & $5917.1 \mathrm{de}(47.1)$ & 6656.7 c (52.9) & $5529.3 \mathrm{~cd}(45.8)$ & $6552.7 \mathrm{~cd}(54.2)$ \\
\hline $\mathrm{D}_{8.25} \times \mathrm{N}_{105}$ & 6900.1 bc (49.4) & $7068.7 \mathrm{~b}(50.6)$ & $5968.7 \mathrm{~b}(46.6)$ & $6850.3 \mathrm{bc}(53.4)$ \\
\hline $\mathrm{D}_{8.25} \times \mathrm{N}_{210}$ & $7442.1 \mathrm{ab}(49.8)$ & 7508.3 a $(50.2)$ & 6652.7 a (47.8) & $7264.3 \mathrm{ab}(52.2)$ \\
\hline $\mathrm{D}_{8.25} \times \mathrm{N}_{315}$ & 7508.0 a (49.8) & 7556.3 a $(50.2)$ & 6924.7 a (48.6) & 7331.0 a $(51.4)$ \\
\hline $\mathrm{D}_{8.25} \times \mathrm{N}_{420}$ & 7802.5 a $(50.5)$ & 7640.4 a (49.5) & 6955.0 a $(48.4)$ & 7415.0 a $(51.6)$ \\
\hline \multicolumn{5}{|c|}{ 变异来源 Source of variation } \\
\hline 种植密度 Density (D) & $* *$ & $* *$ & $* *$ & $* *$ \\
\hline 施氮量 Nitrogen (N) & $* *$ & $* *$ & $* *$ & $* *$ \\
\hline 种植密度 $\times$ 施氮量 $\mathrm{D} \times \mathrm{N}$ & $\mathrm{ns}$ & $* *$ & $\mathrm{~ns}$ & $\mathrm{~ns}$ \\
\hline
\end{tabular}

每列括号内为各器官分配量占总积累量的百分比。处理同表 1 。

The percentage of organ allocation form total accumulation is shown in parentheses. DVO: distribution in vegetative organs; DRO: distribution in reproductive organs. Treatments are the same as those given in Table 1.

表 4 种植密度和施氮量对棉花氮素分配的影响

Table 4 Effects of nitrogen application and planting density on nitrogen distribution in cotton $\left(\mathrm{kg} \mathrm{hm}^{-2}\right)$

\begin{tabular}{|c|c|c|c|c|}
\hline \multirow{2}{*}{$\begin{array}{c}\text { 处理 } \\
\text { Treatment }\end{array}$} & \multicolumn{2}{|c|}{2016} & \multicolumn{2}{|c|}{2017} \\
\hline & $\begin{array}{c}\text { 营养器官分配量 } \\
\text { DVO }\end{array}$ & $\begin{array}{c}\text { 生殖器官分配量 } \\
\text { DRO }\end{array}$ & $\begin{array}{c}\text { 营养器官分配量 } \\
\text { DVO }\end{array}$ & $\begin{array}{c}\text { 生殖器官分配量 } \\
\text { DRO }\end{array}$ \\
\hline \multicolumn{5}{|c|}{ 种植密度 Plant density $\left(\times 10^{4}\right.$ plants $\left.\mathrm{hm}^{-2}\right)$} \\
\hline $\mathrm{D}_{5.25}$ & $96.8 \mathrm{~b}(44.1)$ & $122.4 \mathrm{~b}(55.9)$ & $93.0 \mathrm{c}(43.7)$ & 119.7 c (56.3) \\
\hline $\mathrm{D}_{6.75}$ & $105.4 \mathrm{a}(45.2)$ & 127.6 a $(54.8)$ & $100.8 \mathrm{~b}(44.0)$ & 127.9 a $(56.0)$ \\
\hline $\mathrm{D}_{8.25}$ & $107.3 \mathrm{a}(45.4)$ & 129.1 a $(54.6)$ & 104.2 a (45.7) & $123.0 \mathrm{~b}(54.3)$ \\
\hline \multicolumn{5}{|l|}{ 施氮量 $\mathrm{N}$ rate $\left(\mathrm{kg} \mathrm{hm}^{-2}\right)$} \\
\hline $\mathrm{N}_{0}$ & 81.7 c $(44.6)$ & $101.6 \mathrm{c}(55.4)$ & 75.0 e $(43.6)$ & $97.1 \mathrm{~d}(56.4)$ \\
\hline $\mathrm{N}_{105}$ & $99.3 \mathrm{~b}(45.3)$ & $119.7 \mathrm{~b}(54.7)$ & $92.1 \mathrm{~d}(43.8)$ & $118.3 \mathrm{c}(56.2)$ \\
\hline $\mathrm{N}_{210}$ & $103.3 \mathrm{~b} \quad(43.3)$ & $135.0 \mathrm{a}(56.7)$ & 105.6 c (44.7) & $130.6 \mathrm{~b}(55.3)$ \\
\hline $\mathrm{N}_{315}$ & $114.2 \mathrm{a}(45.0)$ & $139.2 \mathrm{a}(55.0)$ & 109.9 b (44.9) & 134.9 a $(55.1)$ \\
\hline $\mathrm{N}_{420}$ & $117.4 \mathrm{a}(46.2)$ & 136.2 a $(53.8)$ & 114.0 a (45.4) & 136.7 a $(54.6)$ \\
\hline \multicolumn{5}{|c|}{ 种植密度 $\times$ 施氮 量 Plant density $\times \mathrm{N}$ rate } \\
\hline $\mathrm{D}_{5.25} \times \mathrm{N}_{0}$ & $79.2 \mathrm{~g}(44.0)$ & $100.8 \mathrm{f}(56.0)$ & $73.5 \mathrm{i}(43.5)$ & $95.6 \mathrm{~h}(56.5)$ \\
\hline $\mathrm{D}_{5.25} \times \mathrm{N}_{105}$ & $95.6 \mathrm{f}(45.7)$ & 113.4 e $(54.3)$ & $88.1 \mathrm{~h}(43.4)$ & $115.2 \mathrm{~g}(56.6)$ \\
\hline $\mathrm{D}_{5.25} \times \mathrm{N}_{210}$ & $94.0 \mathrm{f}(41.6)$ & 131.9 bc (58.4) & $99.4 \mathrm{fg}(43.6)$ & $128.5 \mathrm{~cd}(56.4)$ \\
\hline $\mathrm{D}_{5.25} \times \mathrm{N}_{315}$ & 108.0 cde $(44.8)$ & $132.9 \mathrm{bc}(55.2)$ & $102.3 \operatorname{def}(43.5)$ & $132.6 \mathrm{bc}(56.5)$ \\
\hline $\mathrm{D}_{5.25} \times \mathrm{N}_{420}$ & 107.0 cde (44.6) & $132.8 \mathrm{bc}(55.4)$ & 101.6 ef (44.5) & $126.5 \mathrm{cde}(55.5)$ \\
\hline $\mathrm{D}_{6.75} \times \mathrm{N}_{0}$ & $82.4 \mathrm{~g}(44.4)$ & $103.2 \mathrm{f}(55.6)$ & 76.2 i (43.5) & $98.9 \mathrm{~h}(56.5)$ \\
\hline $\mathrm{D}_{6.75} \times \mathrm{N}_{105}$ & 103.4 def $(46.1)$ & $121.0 \mathrm{de}(53.9)$ & $94.4 \mathrm{gh}(43.7)$ & 121.4 efg $(56.3)$ \\
\hline $\mathrm{D}_{6.75} \times \mathrm{N}_{210}$ & 106.6 cde (43.7) & $137.2 \mathrm{ab}(56.3)$ & 108.3 cde (43.8) & $138.8 \mathrm{ab}(56.2)$ \\
\hline $\mathrm{D}_{6.75} \times \mathrm{N}_{315}$ & $118.7 \mathrm{~b}(45.6)$ & $141.4 \mathrm{ab}(54.4)$ & 110.9 bc (44.4) & $138.9 \mathrm{ab}(55.6)$ \\
\hline $\mathrm{D}_{6.75} \times \mathrm{N}_{420}$ & $116.1 \mathrm{bc}(46.2)$ & $135.0 \mathrm{ab}(53.8)$ & $114.0 \mathrm{bc}(44.6)$ & $141.4 \mathrm{a}(55.4)$ \\
\hline $\mathrm{D}_{8.25} \times \mathrm{N}_{0}$ & $83.6 \mathrm{~g}(45.4)$ & $100.8 \mathrm{f}(54.6)$ & $75.3 \mathrm{i}(43.8)$ & $96.8 \mathrm{~h}(56.2)$ \\
\hline $\mathrm{D}_{8.25} \times \mathrm{N}_{105}$ & 98.9 ef (44.2) & $124.9 \mathrm{~cd}(55.8)$ & $93.8 \mathrm{gh}(44.2)$ & $118.4 \mathrm{fg}(55.8)$ \\
\hline $\mathrm{D}_{8.25} \times \mathrm{N}_{210}$ & $109.2 \mathrm{bcd}(44.6)$ & $136.0 \mathrm{ab}(55.4)$ & $109.0 \mathrm{~cd}(46.6)$ & $124.6 \operatorname{def}(53.4)$ \\
\hline $\mathrm{D}_{8.25} \times \mathrm{N}_{315}$ & 115.8 bc (44.7) & $143.1 \mathrm{a}(55.3)$ & $116.5 \mathrm{~b}(46.7)$ & $133.3 \mathrm{bc}(53.3)$ \\
\hline $\mathrm{D}_{8.25} \times \mathrm{N}_{420}$ & 129.1 a (47.9) & $140.7 \mathrm{ab}(52.1)$ & $126.4 \mathrm{a}(47.1)$ & 142.1 a $(52.9)$ \\
\hline \multicolumn{5}{|l|}{ 变异来源 Source of variation } \\
\hline 种植密度 Density (D) & $* *$ & $*$ & $* *$ & $* *$ \\
\hline 施氮量 Nitrogen (N) & $* *$ & $* *$ & $* *$ & $* *$ \\
\hline 种植密度 $\times$ 施氮量 $\mathrm{D} \times \mathrm{N}$ & $\mathrm{ns}$ & $\mathrm{ns}$ & $* *$ & $* *$ \\
\hline
\end{tabular}

每列括号内为各器官分配量占总积累量的百分比。处理同表 1 。

The percentage of organ allocation form total accumulation is shown in parentheses. DVO: distribution in vegetative organs; DRO: distribution in reproductive organs. Treatments are the same as those given in Table 1. 
两者互作条件下差异极显著。2016 年，随着种 植密度增加, 氮素分配到营养器官与生殖器官的量 呈升高趋势, $\mathrm{D}_{6.75} 、 \mathrm{D}_{8.25}$ 显著高于 $\mathrm{D}_{5.25}$, 随着施氮量 增加, 分配到营养器官的量呈升高趋势, $\mathrm{N}_{420}$ 显著高 于其他处理, $\mathrm{N}_{105}$ 与 $\mathrm{N}_{210} 、 \mathrm{~N}_{315}$ 与 $\mathrm{N}_{420}$ 间差异不显著, 分配到生殖器官的量呈先升高后降低趋势, $\mathrm{N}_{210}$ 、 $\mathrm{N}_{315} 、 \mathrm{~N}_{420}$ 间差异不显著; 两者互作条件下, 分配到 营养器官的量在 $\mathrm{D}_{8.25} \mathrm{~N}_{420}$ 时取得最大值, 分配到生 殖器官的量在 $\mathrm{D}_{8.25} \mathrm{~N}_{315}$ 时取得最大值, 分配比例分 别为 $47.9 \% 、 55.3 \%$ 。2 017 年，分配到营养器官与生 殖器官的量在不同种植密度和施氮量及其互作下差 异极显著, 随着种植密度增加, 分配到营养器官的 量显著升高, 分配到生殖器官的量则先升高后降低, 且 $\mathrm{D}_{6.75}$ 显著高于 $\mathrm{D}_{5.25} 、 \mathrm{D}_{8.25}$, 随着施氮量增加, 分 配到营养器官的量显著升高, 分配到生殖器官的量 也呈升高趋势, $\mathrm{N}_{315}$ 与 $\mathrm{N}_{420}$ 间差异不显著, 两者互作 条件下, 分配到营养器官和生殖器官的量均在 $\mathrm{D}_{8.25} \mathrm{~N}_{420}$ 时为最大值, 分配比例为 $47.1 \% 、 52.9 \%$ 。 与 2017 年相比, 2016 年氮素积累总量虽大, 但分配 到生殖器官的比例不高, 说明多吸收的氮素没有更 多地分配到生殖器官。

\section{5 产量及其构成因素}

不同年份间棉花产量差异极显著, 其中铃数是 差异的主要因素, 相同年份间种植密度、施氮量及 两者互作对棉花产量均有极显著影响, 其中铃数和 铃重是差异的主要因素, 衣分与品种特性密切相关, 受环境因素和栽培措施的影响较小。2016 年, 随着 密度增加, 皮棉产量先升高后降低, 与 $\mathrm{D}_{8.25}$ 相比, $\mathrm{D}_{5.25} 、 \mathrm{D}_{6.75}$ 皮棉产量显著提高了 $7.0 \% 、 8.3 \%$; 随着
施氮量增加，皮棉产量呈先升高后降低的趋势，最 大值出现在 $N_{210}$, 且 $N_{210}$ 与 $N_{315}$ 差异不显著, 与其 他处理差异显著, 与 $\mathrm{N}_{0}$ 相比, 各施氮处理间皮棉产 量分别提高了 $11.7 \% 、 17.3 \% 、 16.4 \% 、 11.7 \%$ ，种植 密度和施氮量互作下，籽棉和皮棉产量在 $\mathrm{D}_{5.25} \mathrm{~N}_{315}$ 条件下最高, 但与 $\mathrm{D}_{6.25} \mathrm{~N}_{105}$ 和 $\mathrm{D}_{6.25} \mathrm{~N}_{210}$ 差异不显著, 可见, 在一定密度和施氮量范围内棉花产量可保持 相对稳定, 获得棉花高产可以通过适当增加密度降 低施氮量来实现, 由产量构成因素可知, 铃重在 $\mathrm{D}_{5.25} \mathrm{~N}_{210} 、 \mathrm{D}_{5.25} \mathrm{~N}_{315} 、 \mathrm{D}_{6.25} \mathrm{~N}_{210}$ 时显著高于其他处理, 铃数随着密度增加显著提高, 不同施氮处理间无显 著差异, 且均显著高于 $\mathrm{N}_{0}$, 在高密度条件下, 各施 氮处理均显著增加了铃数, 表明种植密度与施氮量 互作下, 通过调控铃数、增加铃重是保持产量稳定 和提高的重要途径。2017 年, 不同种植密度、施氮 量处理间皮棉和籽棉产量的变化趋势与 2016 年相 同，两者互作条件下，皮棉和籽棉在 $\mathrm{D}_{6.25} \mathrm{~N}_{210}$ 和 $\mathrm{D}_{5.25} \mathrm{~N}_{315}$ 条件下均高产, 两处理间差异不显著, 且均 显著高于其他处理, 由产量构成因素可知, 铃重在 $\mathrm{D}_{5.25}$ 与 $\mathrm{D}_{6.75}$ 条件下均显著高于 $\mathrm{D}_{8.25}$, 同一密度不同 施氮量间无显著变化, 铃数随密度提高显著增加, $\mathrm{D}_{5.25}$ 与 $\mathrm{D}_{6.75}$ 条件下不同施氮量间无显著变化，而 $\mathrm{D}_{8.25}$ 条件下过高施氮量显著减少, 可见, 在一定密 度和施氮量范围内棉花产量可保持相对稳定, 增加 密度减少施氮量可以实现棉花高产。与 2016 年相比, 2017 年各处理平均皮棉产量提高了 $3.3 \%$, 年际间的 差异可能是受 2 年棉花生长季气象条件的影响, 2016 年播种后 60 90 d 阴雨寊照天气较多造成营养 生长旺盛, 生殖生长受到抑制, 不利于获得高产。

表 5 增密减氮对棉花产量及其构成因素的影响

Table 5 Effects of increased planting density with reduced nitrogen fertilizer application on cotton yield and yield components

\begin{tabular}{|c|c|c|c|c|c|c|}
\hline $\begin{array}{c}\text { 密度 } \\
\text { Plant density } \\
\left(\times 10^{4} \text { plants } \mathrm{hm}^{-2}\right)\end{array}$ & $\begin{array}{c}\text { 施氮量 } \\
\mathrm{N} \text { rate } \\
\left(\mathrm{kg} \mathrm{hm}^{-2}\right)\end{array}$ & $\begin{array}{c}\text { 铃数 } \\
\text { Boll density } \\
\left(\times 10^{4} \text { bolls } \mathrm{hm}^{-2}\right)\end{array}$ & $\begin{array}{c}\text { 铃重 } \\
\text { Boll weight } \\
\left(\mathrm{g} \mathrm{boll}{ }^{-1}\right)\end{array}$ & $\begin{array}{c}\text { 衣分 } \\
\text { Lint percentage } \\
(\%) \\
\end{array}$ & $\begin{array}{c}\text { 籽棉实产 } \\
\text { Seed cotton yield } \\
\left(\mathrm{kg} \mathrm{hm}^{-2}\right)\end{array}$ & $\begin{array}{l}\text { 皮棉实产 } \\
\text { Lint yield } \\
\left(\mathrm{kg} \mathrm{hm}^{-2}\right)\end{array}$ \\
\hline \multicolumn{7}{|l|}{2016} \\
\hline \multirow{5}{*}{$\mathrm{D}_{5.25}$} & $\mathrm{~N}_{0}$ & $64.6 \mathrm{~d}$ & $5.3 \mathrm{~cd}$ & $41.9 \mathrm{a}$ & $3283.7 \mathrm{e}$ & $1375.1 \mathrm{e}$ \\
\hline & $\mathrm{N}_{105}$ & $71.8 \mathrm{c}$ & $5.6 \mathrm{~b}$ & $41.7 \mathrm{a}$ & $3584.3 \mathrm{~d}$ & $1493.1 \mathrm{~d}$ \\
\hline & $\mathrm{N}_{210}$ & $72.4 \mathrm{c}$ & $5.8 \mathrm{a}$ & $41.6 \mathrm{a}$ & $3998.0 \mathrm{bc}$ & $1662.2 \mathrm{bc}$ \\
\hline & $\mathrm{N}_{315}$ & $71.7 \mathrm{c}$ & $6.0 \mathrm{a}$ & $41.8 \mathrm{a}$ & $4234.3 \mathrm{a}$ & $1769.7 \mathrm{a}$ \\
\hline & $\mathrm{N}_{420}$ & $71.6 \mathrm{c}$ & $5.4 \mathrm{bc}$ & $41.7 \mathrm{a}$ & $3964.7 \mathrm{c}$ & $1653.9 \mathrm{bc}$ \\
\hline \multirow[t]{4}{*}{$\mathrm{D}_{6.75}$} & $\mathrm{~N}_{0}$ & $66.9 \mathrm{~d}$ & $5.6 \mathrm{~b}$ & $41.5 \mathrm{a}$ & $3425.0 \mathrm{e}$ & $1421.1 \mathrm{e}$ \\
\hline & $\mathrm{N}_{105}$ & $76.3 \mathrm{~b}$ & $5.6 \mathrm{~b}$ & $41.5 \mathrm{a}$ & $4126.0 \mathrm{ab}$ & $1713.0 \mathrm{ab}$ \\
\hline & $\mathrm{N}_{210}$ & $78.0 \mathrm{~b}$ & $5.9 \mathrm{a}$ & $41.5 \mathrm{a}$ & $4208.3 \mathrm{a}$ & $1745.3 \mathrm{a}$ \\
\hline & $\mathrm{N}_{315}$ & $76.5 \mathrm{~b}$ & $5.6 \mathrm{~b}$ & $41.7 \mathrm{a}$ & $3898.0 \mathrm{c}$ & $1626.6 \mathrm{c}$ \\
\hline
\end{tabular}


(续表 5)

\begin{tabular}{|c|c|c|c|c|c|c|}
\hline $\begin{array}{c}\text { 密度 } \\
\text { Plant density } \\
\left(\times 10^{4} \text { plants } \mathrm{hm}^{-2}\right) \\
\end{array}$ & $\begin{array}{c}\text { 施氮量 } \\
\mathrm{N} \text { rate } \\
\left(\mathrm{kg} \mathrm{hm}^{-2}\right) \\
\end{array}$ & $\begin{array}{c}\text { 铃数 } \\
\text { Boll density } \\
\left(\times 10^{4} \text { bolls } \mathrm{hm}^{-2}\right)\end{array}$ & $\begin{array}{c}\text { 铃重 } \\
\text { Boll weight } \\
\left(\mathrm{g} \mathrm{boll}{ }^{-1}\right) \\
\end{array}$ & $\begin{array}{c}\text { 衣分 } \\
\text { Lint percentage } \\
(\%) \\
\end{array}$ & $\begin{array}{c}\text { 籽棉实产 } \\
\text { Seed cotton yield } \\
\left(\mathrm{kg} \mathrm{hm}^{-2}\right)\end{array}$ & $\begin{array}{l}\text { 皮棉实产 } \\
\text { Lint yield } \\
\left(\mathrm{kg} \mathrm{hm}^{-2}\right)\end{array}$ \\
\hline$D_{6.75}$ & $\mathrm{~N}_{420}$ & $76.5 \mathrm{~b}$ & $5.6 \mathrm{~b}$ & $41.4 \mathrm{a}$ & $3714.7 \mathrm{~d}$ & $1538.5 \mathrm{~d}$ \\
\hline $\mathrm{D}_{8.25}$ & $\mathrm{~N}_{0}$ & $72.5 \mathrm{c}$ & $5.2 \mathrm{~d}$ & $41.8 \mathrm{a}$ & $3373.0 \mathrm{e}$ & $1409.3 \mathrm{e}$ \\
\hline & $\mathrm{N}_{105}$ & $82.0 \mathrm{a}$ & $5.2 \mathrm{~d}$ & $41.5 \mathrm{a}$ & $3591.7 \mathrm{~d}$ & $1490.3 \mathrm{~d}$ \\
\hline & $\mathrm{N}_{210}$ & $84.7 \mathrm{a}$ & $5.3 \mathrm{~cd}$ & $41.7 \mathrm{a}$ & $3659.3 \mathrm{~d}$ & $1526.8 \mathrm{~d}$ \\
\hline & $\mathrm{N}_{315}$ & $84.2 \mathrm{a}$ & $5.6 \mathrm{~b}$ & $41.8 \mathrm{a}$ & $3581.3 \mathrm{~d}$ & $1497.7 \mathrm{~d}$ \\
\hline & $\mathrm{N}_{420}$ & $83.3 \mathrm{a}$ & $5.3 \mathrm{~cd}$ & $41.8 \mathrm{a}$ & $3609.3 \mathrm{~d}$ & $1506.9 \mathrm{~d}$ \\
\hline \multicolumn{7}{|l|}{2017} \\
\hline \multirow[t]{5}{*}{$\mathrm{D}_{5.25}$} & $\mathrm{~N}_{0}$ & $69.0 \mathrm{f}$ & $5.4 \mathrm{c}$ & $41.2 \mathrm{a}$ & $3391.3 \mathrm{e}$ & $1396.3 \mathrm{e}$ \\
\hline & $\mathrm{N}_{105}$ & $76.0 \mathrm{~d}$ & $5.7 \mathrm{ab}$ & $41.0 \mathrm{a}$ & $3859.3 \mathrm{~d}$ & $1583.7 \mathrm{~d}$ \\
\hline & $\mathrm{N}_{210}$ & $75.8 \mathrm{~d}$ & $5.7 \mathrm{ab}$ & $41.0 \mathrm{a}$ & $4157.7 \mathrm{~b}$ & $1704.7 \mathrm{~b}$ \\
\hline & $\mathrm{N}_{315}$ & $76.7 \mathrm{~d}$ & $5.8 \mathrm{a}$ & $41.1 \mathrm{a}$ & $4429.3 \mathrm{a}$ & $1818.3 \mathrm{a}$ \\
\hline & $\mathrm{N}_{420}$ & $76.3 \mathrm{~d}$ & $5.6 \mathrm{ab}$ & $41.5 \mathrm{a}$ & $4096.3 \mathrm{~b}$ & $1699.0 \mathrm{~b}$ \\
\hline \multirow[t]{5}{*}{$\mathrm{D}_{6.75}$} & $\mathrm{~N}_{0}$ & $69.9 \mathrm{f}$ & $5.5 \mathrm{c}$ & $41.3 \mathrm{a}$ & $3471.0 \mathrm{e}$ & $1433.0 \mathrm{e}$ \\
\hline & $\mathrm{N}_{105}$ & $80.2 \mathrm{c}$ & $5.7 \mathrm{ab}$ & $41.4 \mathrm{a}$ & $4117.7 \mathrm{~b}$ & $1705.7 \mathrm{~b}$ \\
\hline & $\mathrm{N}_{210}$ & $81.5 \mathrm{c}$ & $5.8 \mathrm{a}$ & $41.4 \mathrm{a}$ & $4415.7 \mathrm{a}$ & $1826.3 \mathrm{a}$ \\
\hline & $\mathrm{N}_{315}$ & $80.9 \mathrm{c}$ & $5.6 \mathrm{~b}$ & $41.2 \mathrm{a}$ & $4017.0 \mathrm{bc}$ & $1653.3 \mathrm{bc}$ \\
\hline & $\mathrm{N}_{420}$ & $81.8 \mathrm{c}$ & $5.7 \mathrm{ab}$ & $41.2 \mathrm{a}$ & $3896.0 \mathrm{~cd}$ & $1605.7 \mathrm{~cd}$ \\
\hline \multirow[t]{5}{*}{$\mathrm{D}_{8.25}$} & $\mathrm{~N}_{0}$ & $73.3 \mathrm{e}$ & $5.3 \mathrm{c}$ & $41.0 \mathrm{a}$ & $3519.3 \mathrm{e}$ & $1444.3 \mathrm{e}$ \\
\hline & $\mathrm{N}_{105}$ & $85.3 \mathrm{ab}$ & $5.4 \mathrm{c}$ & $41.5 \mathrm{a}$ & $3770.7 \mathrm{~d}$ & $1564.0 \mathrm{~d}$ \\
\hline & $\mathrm{N}_{210}$ & $85.9 \mathrm{ab}$ & $5.4 \mathrm{c}$ & $41.2 \mathrm{a}$ & $3898.3 \mathrm{~cd}$ & $1607.7 \mathrm{~cd}$ \\
\hline & $\mathrm{N}_{315}$ & $87.6 \mathrm{a}$ & $5.4 \mathrm{c}$ & $41.1 \mathrm{a}$ & $3901.0 \mathrm{~cd}$ & $1605.0 \mathrm{~cd}$ \\
\hline & $\mathrm{N}_{420}$ & $85.1 \mathrm{~b}$ & $5.4 \mathrm{c}$ & $41.4 \mathrm{a}$ & $3778.3 \mathrm{~d}$ & $1564.3 \mathrm{~d}$ \\
\hline \multicolumn{7}{|c|}{ 变异来源 Source of variation } \\
\hline \multicolumn{2}{|l|}{ 年份 Year } & $* *$ & ns & ns & $* *$ & $* *$ \\
\hline \multicolumn{2}{|c|}{ 种植密度 Density (D) } & $* *$ & $* *$ & ns & $* *$ & $* *$ \\
\hline \multicolumn{2}{|c|}{ 施氮量 Nitrogen (N) } & $* *$ & $* *$ & ns & $* *$ & $* *$ \\
\hline \multicolumn{2}{|c|}{ 种植密度 $\times$ 施氮量 $\mathrm{D} \times \mathrm{N}$} & $* *$ & $* *$ & $\mathrm{~ns}$ & $* *$ & $* *$ \\
\hline
\end{tabular}

处理同表 1 。 Treatments are the same as those given in Table 1.

\section{3 讨论}

\section{1 种植密度和施氮量对棉花干物质积累与分 配的影响}

种植密度和施氮量作为棉花生产主要的调控措 施，不仅影响干物质积累与分配，还影响棉花的产 量。干物质积累是棉花产量的物质基础, 群体干物 质保持在适宜的范围内, 有利于协调营养生长与生 殖生长间的矛盾，为棉花高产建立合理的群体基 础 ${ }^{[11-12]}$ 。邢晋等 ${ }^{[13]}$ 研究表明随种植密度的提高群体 干物质呈先升高后降低趋势, 且群体干物质最大值 出现在 10.50 万株 $\mathrm{hm}^{-2}$ 处。马宗斌等 ${ }^{[14]}$ 在黄河滩低 肥力条件下开展研究表明, 施氮量过低时, 干物质 积累量较少; 施氮量 $300 \mathrm{~kg} \mathrm{hm}^{-2}$ 时, 棉花干物质积
累量较大, 且分配到生殖器官的比例较高; 施氮量 $450 \mathrm{~kg} \mathrm{hm}^{-2}$ 时, 有利于营养器官生长, 干物质积累 量最大, 但分配到生殖器官的比例较低。李伶俐等 ${ }^{[15]}$ 研究表明增施氮肥促进了杂交棉的干物质积累, 当 施氮量增加到 $300 \mathrm{~kg} \mathrm{hm}^{-2}$ 后, 促进效果不显著, 在 生殖器官的分配比例明显下降。目前本区域棉花生 产上适宜密度范围为 4.50 5.25 万株 $\mathrm{hm}^{-2}$ 、施氮量 为 $300 \mathrm{~kg} \mathrm{hm}^{-2}$ 左右 ${ }^{[16-19]}$ 。本试验在前人研究基础上 采用适当增加种植密度, 发现随着种植密度和施氮 量增加, $\mathrm{D}_{8.25} \mathrm{~N}_{420}$ 时干物质积累量最大、生殖器官的 分配比例最低, 且表现叶片贪青、营养生长过盛, 不 利于后期棉铃的生长发育, 而通过增加种植密度可 实现最适干物质积累量, 减少施氮量可满足提高生 殖器官分配比例, 增密减氮为提高本区域棉花产量 
提供了重要物质基础。

\section{2 种植密度和施氮量对棉花氮素积累与分配 的影响}

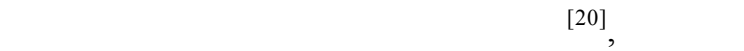
变化对产量形成有一定的影响, 大量研究证实了棉 花氮素的吸收与干物质积累趋势一致, 呈线性正相

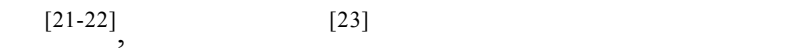
阶段氮素含量与干物质积累量呈线性关系, 生殖阶 段不再有相关性。从本试验干物质和氮素积累的特 征参数来看, 氮素的快速积累期起始时间比干物质 积累早 4 6 d, 说明棉花养分吸收是干物质积累的前 提。本研究表明, 棉花氮素积累与干物质积累变化 趋势一致, 随着种植密度增加, 棉株氮素积累量呈 升高趋势, 增施氮肥可以显著提高氮素积累量, 种 植密度和施氮量互作条件下, 氮素积累量在 $\mathrm{D}_{8.25} \mathrm{~N}_{420}$ 时最大, 随着种植密度和施氮量增加, 分配 到生殖器官的比例下降, $\mathrm{D}_{8.25} \mathrm{~N}_{420}$ 时生殖器官的分配 比例最低, 施氮量过大造成更多的氮素分配到棉株 营养器官中, 导致营养生长过盛, 群体过大, 可见 减少施氮量有利于氮素的高效利用。

\section{3 种植密度和施氮量对棉花产量的影响}

种植密度和施氮量是调节干物质和氮素积累 分配的主要手段, 对棉株的生长发育和产量潜力具 有较大的调控作用 ${ }^{[24-25]}$ 。不同棉区棉花获得高产的 适宜密度不同, 长江流域下游棉区抗虫杂交棉适宜

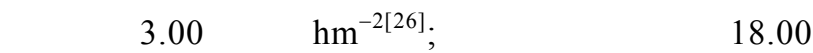
万株 $\mathrm{hm}^{-2}$ 时皮棉获得高产 ${ }^{[27-28]}$; 华北平原棉区 5.10 万株 $\mathrm{hm}^{-2}$ 和 8.70 万株 $\mathrm{hm}^{-2}$ 的密度处理时皮 棉产量最高 ${ }^{[29]}$; 黄河流域棉区种植密度在 4.50 万 株 $\mathrm{hm}^{-2}$ 左右 ${ }^{[30]}$ 。Dong 等 ${ }^{[9]}$ 研究认为盐碱地棉花种 植密度 7.50 万株 $\mathrm{hm}^{-2}$, 施氮量为 $120 \mathrm{~kg} \mathrm{hm}^{-2}$ 时可 得到较高产量; 李鹏程等 ${ }^{[4]}$ 研究表明种植密度 7.50 万株 $\mathrm{hm}^{-2}$ 、施氮量 $112.5 \mathrm{~kg} \mathrm{hm}^{-2}$ 时, 皮棉产量最 高。本研究发现目前棉花生产上的种植密度 5.25 万株 $\mathrm{hm}^{-2}$ 、施氮量 $315 \mathrm{~kg} \mathrm{hm}^{-2}$ 可得到较高产量, 增加种植密度减少施氮量后, 种植密度 6.75 万株 $\mathrm{hm}^{-2}$ 、施氮量为 $210 \mathrm{~kg} \mathrm{hm}^{-2}$ 和 $105 \mathrm{~kg} \mathrm{hm}^{-2}$ 时也能 获得较高产量, 产量构成因素中铃数、铃重是获得 高产的主要因素, 增密减氮后铃数显著增加是棉花 能维持高产的重要保证。

\section{4 结论}

增加种植密度和施氮量可以显著提高棉花中后
期干物质和氮素积累速率、增加干物质和氮素积累 总量, 两者互作下, 增密减氮可充分发挥群体增产 潜力实现氮肥供应与棉株需求之间的平衡，当种植 密度增加到适宜范围时, 通过调控施氮量达到棉株 最适铃数和铃重是高产稳产的重要途径。推荐本地 区棉花种植密度从常规的 5.25 万株 $\mathrm{hm}^{-2}$ 增加到 6.75 万株 $\mathrm{hm}^{-2}$, 施氮量从常规的 $300 \mathrm{~kg} \mathrm{hm}^{-2}$ 第一 年减少为 $105 \mathrm{~kg} \mathrm{hm}^{-2}$, 第二年减少为 $210 \mathrm{~kg} \mathrm{hm}^{-2}$ 。

\section{References}

[1] 喻树迅, 范术丽, 王寒涛, 魏恒玲, 庞朝友. 中国棉花高产育 种研究进展. 中国农业科学, 2016, 49: 3465-3476.

Yu S X, Fan S L, Wang H T, Wei H L, Pang C Y. Progresses in research on cotton high yield breeding in China. Sci Agric Sin, 2016, 49: 3465-3476 (in Chinese with English abstract).

[2] Manderscheid R, Pacholski A, Frühauf C, Weigel H J. Effects of free air carbon dioxide enrichment and nitrogen supply on growth and yield of winter barley cultivated in a crop rotation. Field Crops Res, 2009, 110: 185-196.

[3] Dai J L, Li W J, Tang W, Zhang D M, Li Z H, Lu H Q, Eneji A E, Dong H Z. Manipulation of dry matter accumulation and partitioning with plant density in relation to yield stability of cotton under intensive management. Field Crops Res, 2015, 180: 207-215.

[4] 李鹏程, 董合林, 刘爱忠, 刘敬然, 孙水, 王国平, 刘绍东, 赵 新华, 李亚兵. 植密度氮肥互作对棉花产量及氮素利用效率 影响. 农业工程学报, 2015, 31(23): 122-130.

Li P C, Dong H L, Liu A Z, Liu J R, Sun M, Wang G P, Liu S D, Zhao X H, Li Y B. Effects of planting density and nitrogen fertilizer interaction on yield and nitrogen use efficiency of cotton. Trans CSAE, 2015, 31(23): 122-130 (in Chinese with English abstract).

[5] 李小勇, 周敏, 王涛, 张兰, 周广生, 萠婕. 种植密度对油菜 机械收获关键性状的影响. 作物学报, 2018, 44: 278-287.

Li X Y, Zhou M, Wang T, Zhang L, Zhou G S, Kuai J. Effects of planting density on the mechanical harvesting characteristics of semi-winter rapeseed. Acta Agron Sin, 2018, 44: 278-287 (in Chinese with English abstract).

[6] 徐娇, 孟亚利, 睢宁, 宋为超, 周治国. 种植密度对转基因棉 氮、磷、钾吸收和利用的影响. 植物营养与肥料学报, 2013, 19: 174-181.

Xu J, Meng Y L, Sui N, Song W C, Zhou Z G. Effects of planting density on uptake and utilization of N, P and $\mathrm{K}$ of transgenic cotton. Plant Nutr Fert Sci, 2013, 19:174-181 (in Chinese with English abstract).

[7] 曹胜彪, 张吉旺, 董树亭, 刘鹏, 赵斌, 杨今胜. 施氮量和种 植密度对高产夏玉米产量和氮素利用效率的影响. 植物营养 与肥料学报, 2012, 18: 1343-1353.

Cao S B, Zhang J W, Dong S T, Liu P, Zhao B, Yang J S. Effects of nitrogen rate and planting density on grain yield and nitrogen utilization efficiency of high yield summer maize. Plant Nutr Fert Sci, 2012, 18: 1343-1353 (in Chinese with English abstract). [8] Yang G Z, Luo X J, Nie Y C, Zhang X L. Effects of plant density 
on yield and canopy microenvironment in hybrid cotton. Integr Agric, 2014, 13: 2154-2163.

[9] Dong H Z, Li W J, Egrinya E A, Zhang D M. Nitrogen rate and plant density effects on yield and late-season leaf senescence of cotton raised on a saline field. Field Crops Res, 2012, 126: 137-144.

[10] 李鹏程, 董合林, 刘爱忠, 刘敬然, 李如义, 孙水, 李亚兵, 毛 树春. 施氮量对棉花功能叶片生理特性、氮素利用效率及产量 的影响. 植物营养与肥料学报, 2015, 21: 81-91.

Li P C, Dong H L, Liu A Z, Liu J R, Li R Y, Sun M, Li Y B, Mao $\mathrm{S} C$. Effects of nitrogen application rates on physiological characteristics of functional leaves, nitrogen use efficiency and yield of cotton. Plant Nutr Fert Sci, 2015, 21: 81-91 (in Chinese with English abstract).

[11] 祝珍珍, 陈亮, 杨国正, 宋学贞, 王德鹏, 陈求柱, Mokhele B. 国内棉花干物质及养分积累与分配研究进展. 江西棉花, 2011, 3(3): 7-10.

Zhu Z Z, Chen L, Yang G Z, Song X Z, Wang D P, Chen Q Z, Mokhele B. Study progress on dry matter and nutrient accumulation distribution of China cotton. Jiangxi Cotton, 2011, 33(3): 7-19 (in Chinese with English abstract).

[12] 叶欣, 王永东, 李瑞雪. 不同品种棉花干物质积差异对比研究. 西南农业大学学报, 2004, 26: 749-752.

Ye X, Wang Y D, Li R X. Comparative studies of dry matter accumulation in different cotton varieties. $J$ Southwest Agric Univ, 2004, 26: 749-752 (in Chinese with English abstract).

[13] 邢晋, 张思平, 赵新华, 问贞贞, 魏然, 张立祯. 种植密度和 缩节胺互作对棉花株型及产量的调控效应. 棉花学报, 2018, 30: 53-61.

Xing J, Zhang S P, Zhao X H, Yan Z Z, Wei R, Zhang L Z. Interaction of plant density with mepiquat chloride affects plant architecture and yield in cotton. Cotton Sci, 2018, 30: 53-61 (in Chinese with English abstract).

[14] 马宗斌, 严根土, 刘桂珍, 黄群, 李伶俐, 朱伟. 施氮量对黄 河滩区棉花叶片生理特性干物质积累及产量的影响. 植物营 养与肥料学报, 2013, 19: 849-857.

Ma Z B, Yan G T, Liu G Z, Huang Q, Li L L, Zhu W. Effects of nitrogen application rates on main physiological characteristics of leaves, dry matter accumulation and yield of cotton cultivated in the Yellow River bottomlands. Plant Nutr Fert Sci, 2013, 19: 849-857 (in Chinese with English abstract).

[15] 李伶俐, 房卫平, 谢德意, 马宗斌, 杜远仿, 张东林. 施氮量 对杂交棉干物质积累、分配和氮磷钾吸收、分配与利用的影 响. 棉花学报, 2010, 22: 347-353.

Li L L, Fang W P, Xie D Y, Ma Z B, Du Y F, Zhang D L. Effects of nitrogen application rate on dry matter accumulation and $\mathrm{N}, \mathrm{P}$, $\mathrm{K}$ uptake and distribution in different organs and utilization of hybrid cotton under high-yield cultivated condition. Cotton Sci, 2010, 22: 347-353 (in Chinese with English abstract).

[16] 王士红, 杨中旭, 李秋芝, 李海涛, 尹会会, 李䑣. 鲁西地区 抗虫棉品种篎选试验. 山东农业科学, 2013, 45(12): 5-7.

Wang S H, Yang Z X, Li Q Z, Li H T, Yin H H, Li T. Screening test of insect-resistant cotton varieties in western Shandong. Shandong Agric Sci, 2013, 45(12): 5-7 (in Chinese).

[17] 王家宝, 王留明, 姜辉, 赵军胜, 陈芗, 高明伟, 王秀丽, 董合 忠. 高产稳产型棉花品种鲁棉研 28 号选育及其栽培生理特性
研究. 棉花学报, 2014, 26: 569-576.

Wang J B, Wang L M, Jiang H, Zhao J S, Chen Y, Gao M W, Wang X L, Dong H Z. Breeding of high and stable-yielding cotton variety SCRC28 and its physiological characteristics for cultivation. Cotton Sci, 2014, 26: 569-576 (in Chinese with English abstract).

[18] 卢合全, 李振怀, 李维江, 孔祥强, 代建龙, 唐薇, 张冬梅, 董 合忠. 适宜轻简栽培的棉花品种 K836 的选育及高产简化栽培 技术. 中国棉花, 2015, 42(6): 33-37.

Lu H Q, Li Z H, Li W J, Kong X Q, Dai J L, Tang W, Zhang D M, Dong H Z. Breeding of cotton cultivar K836 suitable for extensive farming and its high-yielding cultivation techniques. China Cotton, 2015, 42(6): 33-37 (in Chinese with English abstract).

[19] 尹会会, 李秋芝, 李海涛, 商娜, 张晗, 李粀, 王士红, 杨中旭. 鲁西地区不同类型土壤对棉花产量及其构成因素与成铃时空 分布的影响. 中国农学通报, 2016, 32(36): 87-90.

Yin H H, Li Q Z, Li H T, Shang N, Zhang H, Li T, Wang S H, Yang Z X. Effect of different soil textures on cotton yield, composition factors and boll spatial-temporal distribution in western Shandong. Chin Agric Sci Bull, 2016, 32(36): 87-90 (in Chinese with English abstract).

[20] 郑剑超, 问曼曼, 张巨松, 高丽丽, 石洪亮, 郑慧, 张玉玲. 遮 荫条件下氮肥运筹对棉花生长和氮素积累的影响. 植物营养 与肥料学报, 2016, 22: 94-103.

Zheng J C, Yan M M, Zhang J S, Gao L L, Shi H L, Zheng H, Zhang Y L. Effects of nitrogen application on growth and nitrogen accumulation of cotton under shading condition. Plant Nutr Fert Sci, 2016, 22: 94-103 (in Chinese with English abstract).

[21] 薛晓萍, 郭文琦, 王以琳, 张丽娟, 周治国. 不同施氮水平下 棉花生物量动态增长特征研究. 棉花学报, 2006, 18: 323-326.

Xue X P, Guo W Q, Wang Y L, Zhang L J, Zhou Z G. Research on dynamic increase characteristics of dry matter of cotton at different nitrogen levels. Cotton Sci, 2006, 18: 323-326 (in Chinese with English abstract).

[22] 李春艳, 文如意, 石洪亮, 严青青, 张巨松. 海岛棉与陆地棉 干物质积累与氮素吸收分配的特点. 干旱地区农业研究, 2017, 35(1): 175-181.

Li C Y, Wen R Y, Shi H L, Yan Q Q, Zhang J S. Dry matter and nitrogen accumulation distribution on island cotton and upland cotton. Agric Res Arid Areas, 2017, 35(1): 175-181 (in Chinese with English abstract).

[23] 娄善伟, 马腾飞, 托合提·艾买提, 张怀军, 王大光, 边洋, 司 地克江, 张鹏忠. 新疆农业科学, 2017, 54: 2182-2189.

Lou S W, Ma T F, Aimait T, Zhang H J, Wang D G, Bian Y, Sidi K J, Zhang P Z. Study on the correlation between nitrogen content and dry matter accumulation in cotton. Xinjiang Agric Sci, 2017, 54: 2182-2189 (in Chinese with English abstract).

[24] 徐新朋, 周卫, 梁国庆, 孙静文, 王秀斌, 何萍, 徐芳森, 余喜 初. 氮肥用量和密度对双季稻产量及氮肥利用率的影响. 植 物营养与肥料学报, 2015, 21: 763-772.

Xu X P, Zhou W, Liang G Q, Sun J W, Wang X B, He P, Xu F S, Yu X C. Effects of nitrogen and density interactions on grain yield and nitrogen use efficiency of double-rice systems. Plant Nutr Fert Sci, 2015, 21: 763-772 (in Chinese with English abstract).

[25] 杨艳君, 王宏富, 郭平毅, 王玉国, 原向阳, 邢国芳, 邵东红, 祁祥, 解丽丽, 聂萌恩, 郭俊, 宁娜. 施肥和密度对张杂谷 5 
号光合特性及产量的影响. 植物营养与肥料学报, 2013, 19: 566-576.

Yang Y J, Wang H F, Guo P Y, Wang Y G, Yuan X Y, Xing G F, Shao D H, Qi X, Xie L L, Nie M E, Guo J, Ning N. Effects of fertilization and density on photosynthetic characteristics and yield of hybrid foxtail millet. Plant Nutr Fert Sci, 2013, 19: 566-576 (in Chinese with English abstract).

[26] 刘瑞显, 史伟, 徐立华, 杨长琴, 郭文琦, 张培通. 长江下游 棉区抗虫杂交棉适宜密度研究. 棉花学报, 2010, 22: 634-638.

Liu R X, Shi W, Xu L H, Yang C Q, Guo W Q, Zhang P T. Planting density of insect-resistant hybrid cotton in lower reaches of Yangtze River Valley. Cotton Sci, 2010, 22: 634-638 (in Chinese with English abstract).

[27] 张旺锋, 王振林, 余松烈, 李少昆, 房建, 童文崧. 种植密度 对新疆高产棉花群体光合作用、冠层结构及产量形成的影响. 植物生态学报, 2004, 28: 164-171

Zhang W F, Wang Z L, Yu S L, Li S K, Fang J, Tong W S. Effects of planting density on canopy photosynthesis, canopy structure and yield formation of high-yield cotton in Xinjiang, China. Chin
Plant Ecol, 2004, 28: 164-171 (in Chinese with English abstract). [28] 娄善伟, 高云光, 郭仁松, 赵强, 张巨松. 不同栽培密度对棉 花植株养分特征及产量的影响. 植物营养与肥料学报, 2010, 16: 953-958.

Lou S W, Gao Y G, Guo R S, Zhao Q, Zhang J S. Effects of planting density on nutrition characteristics and yield of cotton. Plant Nutr Fert Sci, 2010, 16: 953-958 (in Chinese with English abstract).

[29] 支晓宇, 毛树春, 韩迎春, 李亚兵, 杜文丽, 李小新, 王国平, 范正义, 杨北方, 冯璐. 密度对棉花产量及棉铃内部产量构成 的影响. 棉花学报, 2015, 27: 216-222.

Zhi X Y, Mao S C, Han Y C, Li Y B, Du W L, Li X X, Wang G P, Fan Z Y, Yang B F, Feng L. Effects of cultivars and planting density on yield components and seed characteristics on cotton. Cotton Sci, 2015, 27: 216-222 (in Chinese with English abstract).

[30] Zhang D M, Luo Z, Liu S H, Li W J, Tang W, Dong H Z. Effects of deficit irrigation and plant density on the growth, yield and fiber quality of irrigated cotton. Field Crops Res, 2016, 197: 1-9. 